Strain-Rate Sensitivity of Strength in Macro-to-Micro-to-Nano Crystalline Nickel

\author{
by \\ Ryan Humphrey, BSME \\ A Thesis \\ In \\ MECHANICAL ENGINEERING \\ Submitted to the Graduate Faculty \\ of Texas Tech University in \\ Partial Fulfillment of \\ the Requirements for \\ the Degree of \\ MASTERS OF SCIENCE
}

IN

\title{
MECHANICAL ENGINEERING
}

Approved

Alan Jankowski, PhD

Chairperson of Committee

Jahan Rasty, PhD

Iris V. Rivero, $\mathrm{PhD}$

Ralph Ferguson

Dean of the Graduate School

December, 2010 
(C) Copyright, 2010 Ryan Humphrey 


\section{ACKNOWLEDGMents}

I would sincerely like to thank Dr. Alan Jankowski for giving me the opportunity to conduct research in a field of great interest to me and also taking the time to periodically review my work and offer positive criticisms; I have learned an innumerable amount not only working in the nano-materials lab, but just about life in general from him and am greatly appreciative. Secondly I would like to thank doctoral candidate H.S. Tanvir Ahmed whom worked alongside me in the nano-materials lab, the assistance and guidance he provided during my graduate career were invaluable and extremely beneficial. I would like to thank my thesis committee Dr. Jahan Rasty and Dr. Iris Rivero for their expertise and assistance in finishing my graduate degree. I also thank the Mechanical Engineering Department and Texas Tech University for admitting me to the Graduate School and supporting my thesis. Lastly, I'd like to thank my family and friends, without their constant encouragement and help, I would not be in the position I am in today. 


\section{TABLE OF CONTENTS}

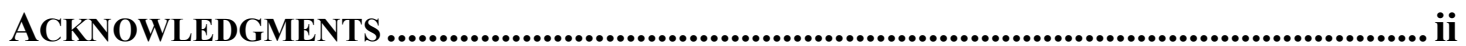

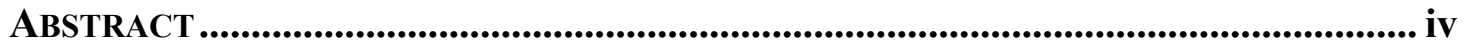

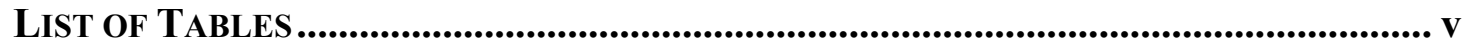

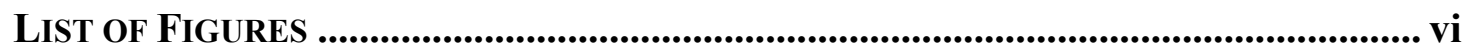

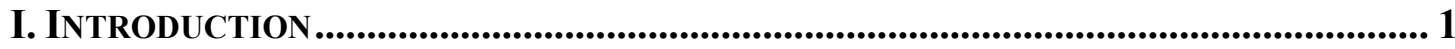

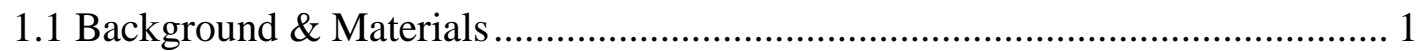

II. ANALYTICAL \& EXPERIMENTAL METHODS........................................................ 5

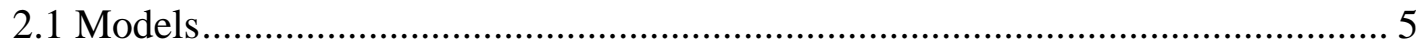

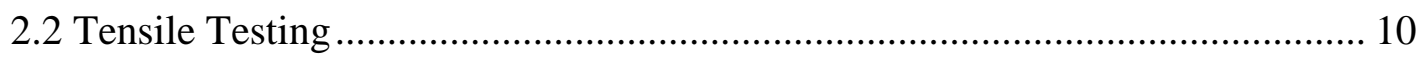

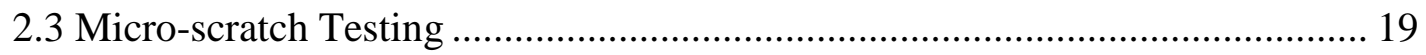

III. EXPERIMENTAL RESULTS ............................................................................ 24

3.1 Analysis of Tensile Testing Results .............................................................. 24

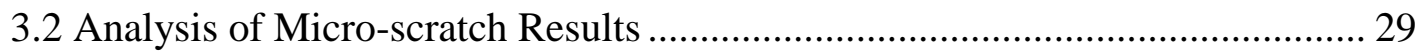

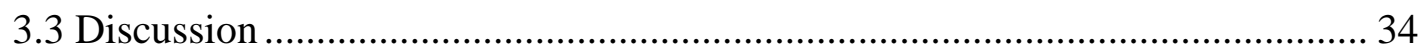

IV. CONCLUSIONS....................................................................................................... 36

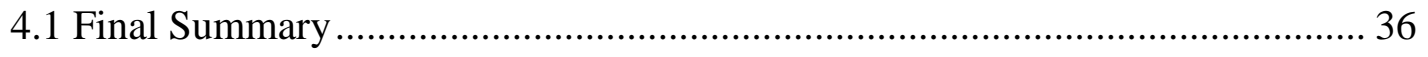

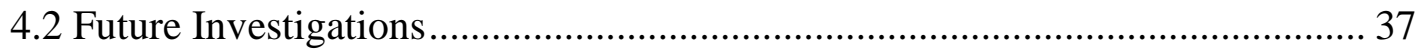

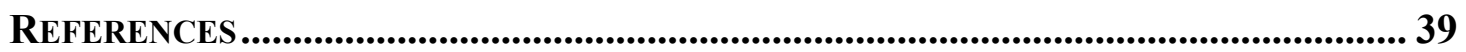

A. SRS AND ACTIVATION VOLUME CALCULATIONS............................................ 42 


\begin{abstract}
The strain-rate sensitivity of strength is a key parameter to evaluate the deformation mechanism in crystalline materials. It is widely reported that many metals strengthen with increasing strain rate, wherein an increase in the strain-rate exponent occurs as the grain size decreases. The strain-rate sensitivity exponent as evaluated from a power-law relationship between yield strength and strain rate is thought to increase when the deformation mechanisms change. As increase in the strain-rate occurs, strengthening is attributable to alloy content, then to dislocation activity, and finally to an increase in effective mass - also known as the phonon drag regime. We will evaluate the behavior of nickel over eight-orders of magnitude change in strain rate to see if the change in strain-rate exponent is affected by the scale of the grain size from the macro- to micro- to nano- scale range as the strain rate increases.

In this study, tensile testing is used to measure the strain-rate dependence of the tensile strength on the grain size in crystalline nickel foils. Similarly, micro-scratch testing is used to determine the strain-rate dependence of the scratch hardness variation with scratch velocity. Results for these two tests methods are compiled for strain rates that range from 0.00001 to $1000 \mathrm{sec}^{-1}$. It is found that these mechanical test results can be directly compared, and the increase in strain rate sensitivity exponent with increasing strain rate is slower for nanocrystalline than for microcrystalline nickel.
\end{abstract}




\section{LIST OF TABLES}

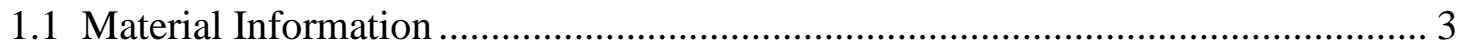

3.1 Rate Sensitivity Exponent (m) and Activation Volume ( $\left.\mathrm{v}^{*}\right)$................................. 27

3.2 Summary of Strain-Rate Sensitivity Exponent (m) Results.................................... 32 


\section{LIST OF FIGURES}

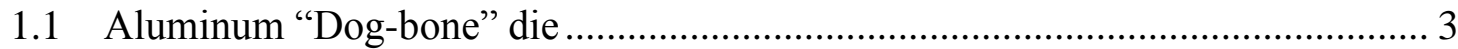

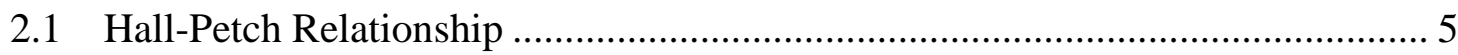

2.2 Difference between rate sensitivity and strain hardening ............................. 6

2.3 Analytical Model of behavior of micro/nano materials through

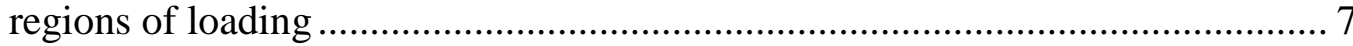

2.4 Universal Tensile Test Machine ....................................................................... 10

2.5 Annealed/Rolled Ni Samples after Milling .................................................. 12

2.6 Nano-crystalline Ni Samples................................................................... 12

2.7 Annealed Ni Foil at Four Strain Rates ....................................................... 14

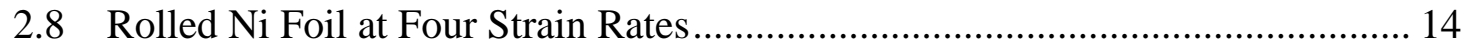

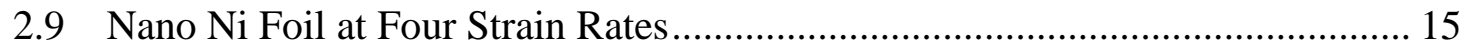

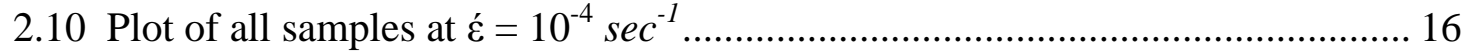

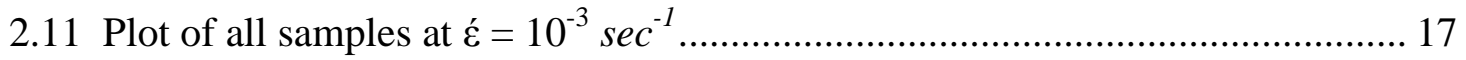

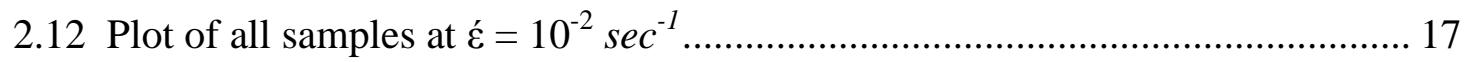

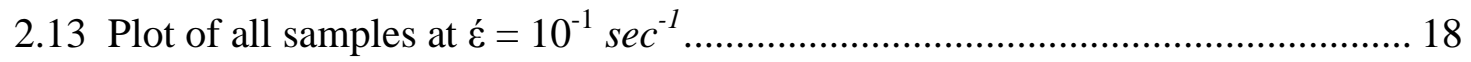

2.14 Micro-Scratch Test Machine .......................................................................... 19

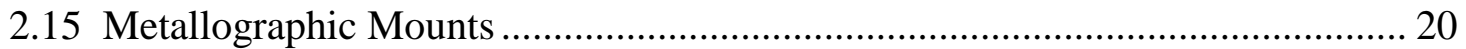

2.16 Schematic of Fabricated Mounts......................................................................... 22

$2.17 \& 2.18 \mathrm{Nc}$ and Annealed Ni post scratch .................................................... 23

3.1 Tensile Test Strain-Rate Exponent ................................................................ 24

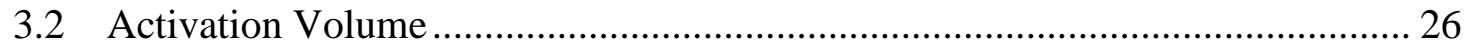

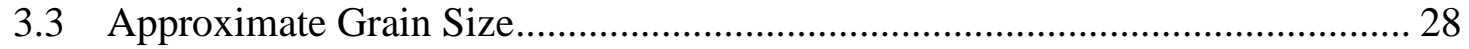

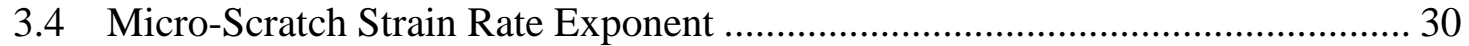

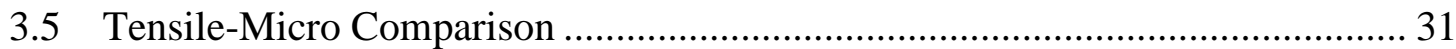

A.1 SRS Exponent of Annealed Sample - Tensile Testing .................................... 42

A.2 SRS Exponent of Rolled Sample - Tensile Testing ....................................... 42

A.3 SRS Exponent of Nano_2 Sample - Tensile Testing ....................................... 43

A.4 SRS Exponent of Nano_1 Sample - Tensile Testing ..................................... 43

A.5 SRS Exponent of Annealed Sample - Micro-scratch Testing .......................... 44

A.6 SRS Exponent of Rolled Sample - Micro-scratch Testing .............................. 44 
A.7 SRS Exponent of Nano_2 Sample - Micro-scratch Testing ............................ 45

A.8 SRS Exponent of Nano_1 Sample - Micro-scratch Testing .............................. 45

A.9 Activation Volume Annealed Sample......................................................... 46

A.10 Activation Volume Rolled Sample ................................................................ 46

A.11 Activation Volume Nano_2 Sample .............................................................. 47

A.12 Activation Volume Nano_1 Sample ....................................................... 47 


\section{CHAPTER I}

\section{INTRODUCTION}

\subsection{Background \& Materials}

Mechanical properties are shown to be sensitive to different test conditions, such as rate of loading, or the deformation rate. This relationship can play a key role in modern engineering applications, as it is shown that different deformation rates can produce significantly different values for strength and hardness $[1,2,3,5,7,9,12]$. Alongside this, the crystal or grain size is shown to play a key role in strength of materials as well, through the Hall-Petch relation. One way to increase strength without a significant loss of ductility is to decrease the grain size. However, what remains to be seen is how grain size will affect the strengthening mechanism through a wide range of deformation rates. A quantitative measure can be employed to evaluate the relationship between strength and deformation rate, strain-rate sensitivity. Strainrate sensitivity is a measure how a material will respond to different deformation, or strain rates, in terms of strength. Through different methods, delaying the onset of plastic deformation without entering into the plastic regime, as with strain hardening, is the main principle of rate sensitivity. The objectives of this study are twofold: first, to observe if it is possible to directly compare dynamic indentation methods to classic tensile testing by measuring the strain rate sensitivity over eight orders of magnitude of deformation rates; and secondly, to observe what role grain size plays on strengthening mechanisms through this wide range. Work has been done $[1,2,3,5]$ to this effect for slower strain rates, mainly in the range of $10^{-5}$ to $10^{-3}$ for macro to nano- 
crystalline grain sizes using tensile testing as well as normal indentation methods, such as normal indentation. However, over the range proposed in this study with dynamic indentation methods, little has been done. In staying with the convention, if indeed there is no deviation from Hall-Petch, an inverse relation exists between strain-rate sensitivity and activation volume. Much work has been done to show this experimentally, as well as key parameters that can also show a dependence of strainrate sensitivity as well as activation volume, such as temperature $[11,12]$.

Four main material samples were used in this experiment. Two nickel foil samples in the ultrafine grain to coarse grain regime were obtained from the Alfa Aesar Company with a thickness reported of $.025 \mathrm{~mm}$, which was verified with a micrometer as well as microscope measurements. One foil had been previously fully annealed with a reported purity of $99.50 \%$ which was assumed to have the largest grain size of all samples, while the other foil was mechanically rolled with a reported purity of $99.99 \%$, which was considered possibly in the UG regime. These two Ni foils represent the macro/microcrystalline samples. Two different nanocrystalline Ni samples with thicknesses between $50-100 \mu \mathrm{m}$ were synthesized by electro-deposition using a Ni-sulfate; Ni-Chloride; Boric acid solution. A variation in the pulse conditions $[13,14]$ including current density and cell potential is empirically formulated to predicatively produce two unique specimens that are differentiated solely by their nanocrystalline grain size. 
Table 1.1 : Material Information

Material Average Thickness $(\mu \mathrm{m}) \quad$ Process

\begin{tabular}{lcc}
\hline Ni Foil 1 & 25 & Annealed \\
\hline Ni Foil 2 & 25 & Rolled \\
\hline ncNi Sample 1 & $50-100$ & Electrodeposited \\
\hline ncNi Sample 2 & $50-100$ & Electrodeposited \\
\hline
\end{tabular}

An aluminum die was designed and used for fabrication of "dog-bone" shape samples for tensile testing with a reduced cross section in the middle of the sample as seen in Figure 1. The resulting geometry of the milled samples included a gage length of $10 \mathrm{~mm}$ with a uniform width of $2 \mathrm{~mm}$.

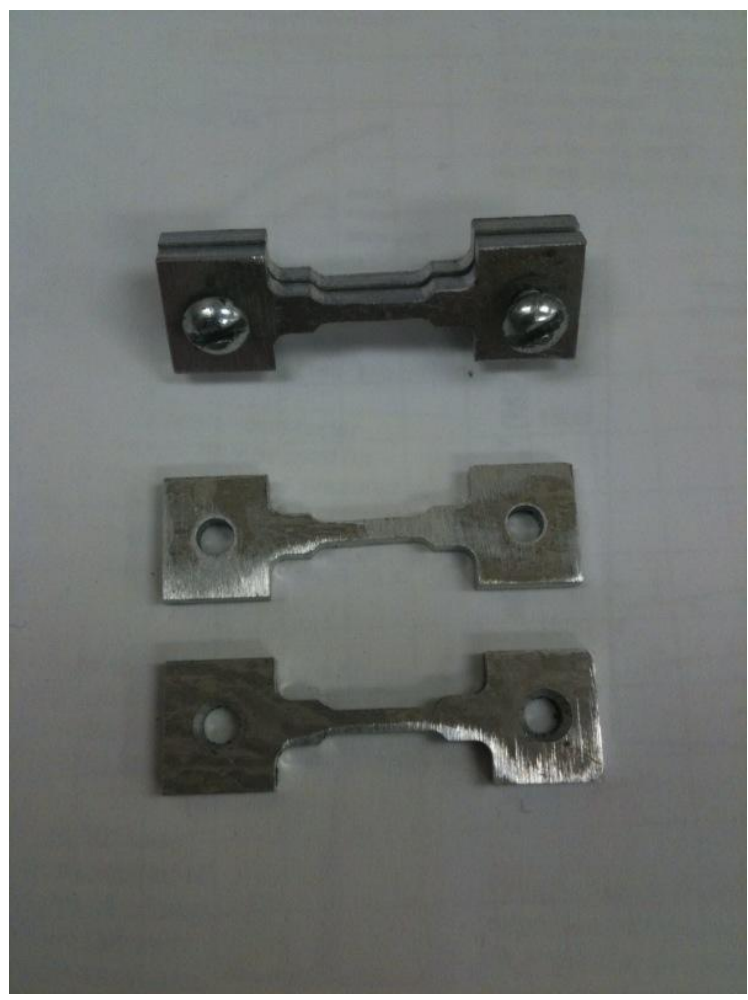

Figure 1.1 : Aluminum "Dog-bone" die 
This aluminum die was used with the annealed nickel samples as well as the mechanically rolled samples, as they were produced in flat sheets. The electrodeposited nanocrystalline samples were already cut into small strips with varying thickness around the order of $1 \mathrm{~mm}$. Theses samples had a slight tapered cut $(\sim 10 \%)$ in that the center cross section had a smaller width that the top and bottom. This was done in an attempt to produce localized failure in the gage length instead of in where the tensile tester grips held the samples. Nickel was chosen as the material of study due the great amount of work with similar face center cubic structure materials which would provide a direct comparison for the results of using a different test method as well as its apparent sensitivity to deformation rates [2,12], and finally for its superb properties and common uses in the industry in alloys. 


\section{Chapter II}

\section{Analytical \& EXPerimental Methods}

\subsection{Models}

It is widely accepted that one way to increase strength in nanocrystalline metals is to decrease the grain size as in the Hall-Petch relation [20,22]. Figure 2.1 shows this relationship between grain size reduction and the resulting increase in strength described in equation 2.1.

$$
\sigma_{\mathrm{y}}=\sigma_{\mathrm{o}}+\frac{\mathrm{K}_{\sigma}}{\sqrt{\mathrm{h}_{\mathrm{g}}}}
$$

Here $\sigma_{y}$ stand for the yield stress, $\mathrm{h}_{\mathrm{g}}$ stands for the grain size, and $\sigma_{o}$ is the intrinsic friction stress (the resistance of the lattice to dislocation movement). Finally $K_{\sigma}$ stands for the slope of the plotted graph, which is a material specific constant.
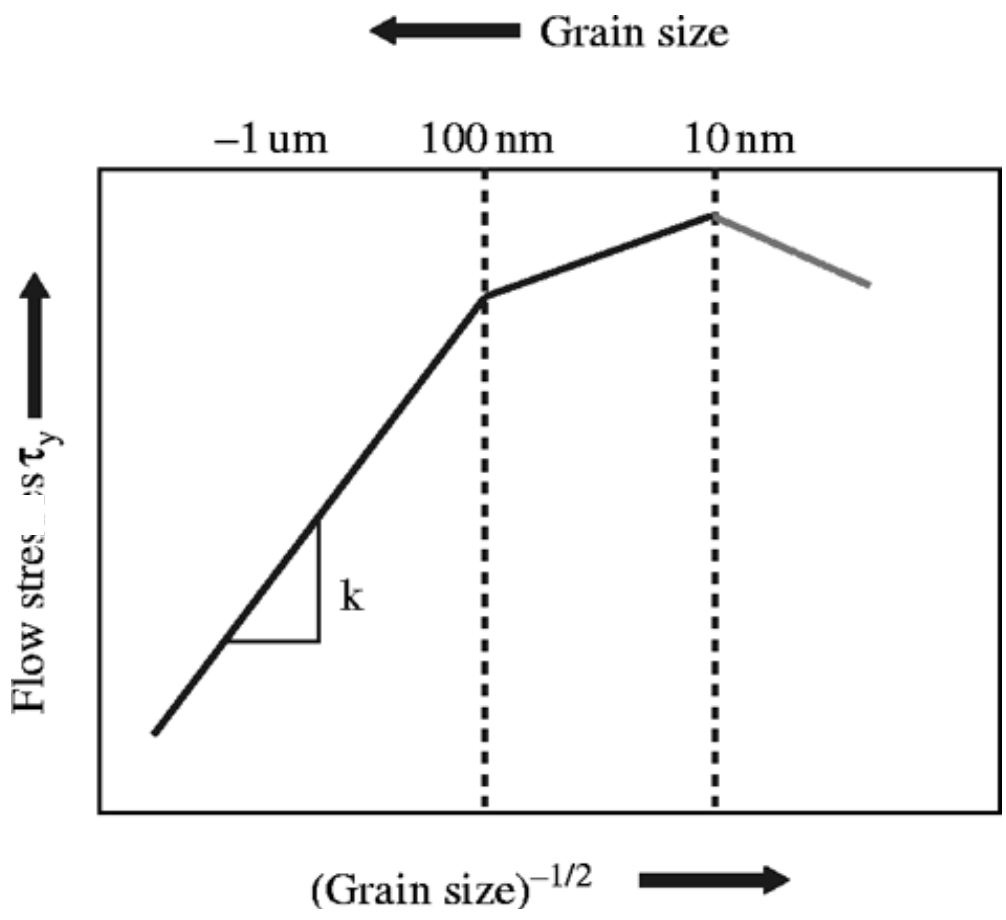

Figure 2.1: Hall-Petch Relationship 
Another key parameter to evaluate the deformation mechanism in crystalline materials is the strain rate sensitivity. It is widely reported that many metals strengthen with increasing strain rate, wherein an increase in the strain-rate sensitivity exponent (m) occurs as the grain size decreases $[1,2,8,9,11,12]$. The strain-rate sensitivity exponent (m) is evaluated from the power-law relationship, with $\mathrm{C}$ as a constant, between yield strength $(\sigma)$ and strain rate $(\varepsilon)$ as in equation 2.2 also known as the Dorn Equation.

$$
\sigma=C \cdot \dot{\varepsilon}^{m}
$$

This rate sensitivity should not be confused with strain hardening effects in materials, as this equation is also similar. Figure 2.2 shows the graphical difference between strain rate sensitivity and strain hardening.

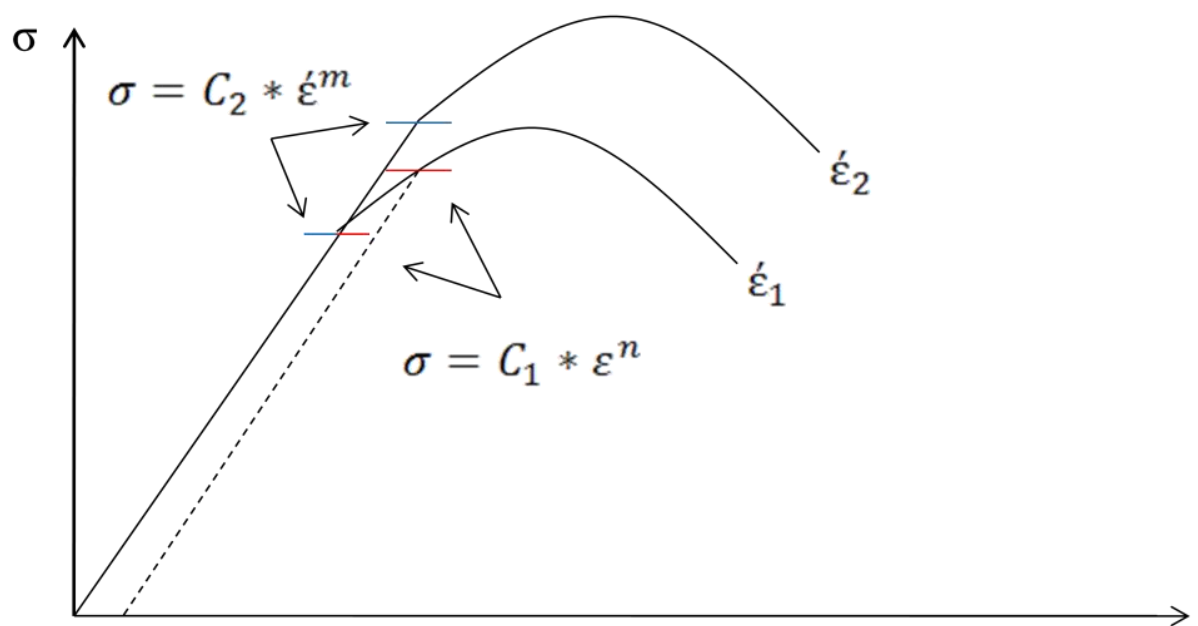

$\varepsilon$

Figure 2.2: Difference between rate sensitivity and strain hardening

The figure shows the two red lines corresponding to strain hardening effects denoted by exponent (n), while the two blue lines represent the rate sensitivity 
exponent (m). In strain hardening, the yield point is moved along the curve at one given strain rate until the ultimate stress point is reached, where as in rate-sensitivity, the yield point is shifted without regard to any changed that may occur in the plastic deformation regime. The yield point is measured using the proportional limit to avoid any compounding effects that can be introduced from strain hardening as would be the case using an offset method to determine yield stress. Once the experimental tests had been carried out, and measurements taken of the yield point at each strain rate, the results are plotted against strain rate to observe the strain rate sensitivity effect following equation 2.2. From other works it has been shown that different zones or "regions" naturally develop within broad ranges of strain rates [6]. These different regions develop because of a difference in primarily mechanism governing strength. Figure 2.3 shows these different regions with a new model that we propose as to how microcrystalline and nanocrystalline metals will behave for strain-rates that vary from just above the creep regime into the phonon-drag regime.

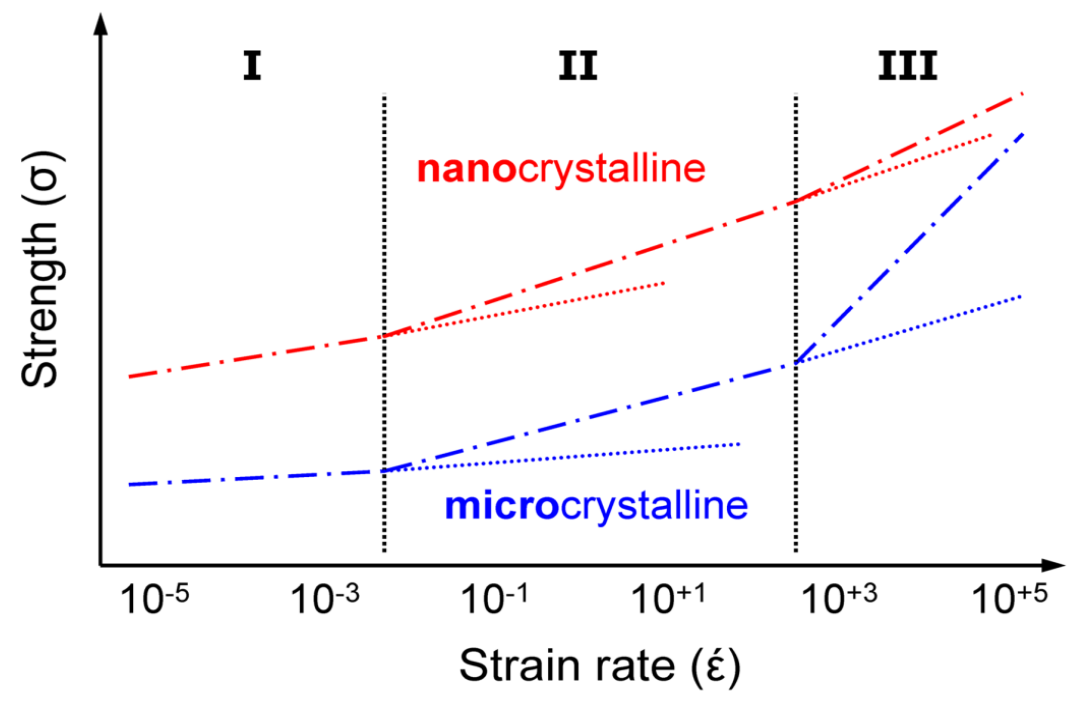

Figure 2.3: Analytical Model of behavior of micro/nano materials through regions of loading 
In Figure 2.3, region I corresponds to low rate rates, on the range of $10^{-5}$ to $10^{-3}$ $\mathrm{sec}^{-1}$ and the primary mechanism attributed to strengthening is solution chemistry, or alloy content. Predominantly friction stress is tied directly to alloy content, therefore as the alloy content in a material increases, so does the friction stress. The result is a metal that is least sensitive to strain rate [6]. In region I, experimental observation [2.15] shows that $(\mathrm{m})$ is greater nanocrystalline metals than for microcrystalline metals. Moving into the range of $10^{-2}$ to $10^{+3} \mathrm{sec}^{-1}$ region II is entered which represents the intermediate ranges in terms of slowest to fastest. In this region, dislocation based activity is the main mechanism of strengthening. The structural state of the material, dislocation density and interaction all play the major role. In region II as in region I, the model shows an increase in strain rate sensitivity for both microcrystalline and nanocrystalline materials. However, microcrystalline materials should have a larger increase than for nanocrystalline materials since strength values will converge [16] at ultra high strain rates. Although nanocrystalline materials could have a theoretically higher value of strain rate sensitivity in this region the slope for the microcrystalline materials is increasing more rapidly than is the one for the nanocrystalline materials. Finally, region III encompasses those rates that are above $10^{+3} \mathrm{sec}^{-1}$ which include the fastest strain rates from the entire range. This region includes the effects of "phonon drag" that can be considered an increase in "effective mass". This region can be thought of as moving too fast for dislocation based activity, and more on the scale of atoms. An electron moves past atoms in the lattice its charge distorts or polarizes the nearby lattice. This effect leads to a decrease in the electron 
(or hole, as may be the case) mobility, which results [6] in a decreased conductivity. This region is typically achieved experimentally by the Split Hopkinson pressure bar test (SHPB). Nano-scratch techniques are also proposed as a viable test method [5] but those tests are beyond the scope of this study. Beyond region III, studies of strain rates reaching $10^{7} \mathrm{sec}^{-1}$ suggest [17] a possible deformation maxima value for which the metals eventually approach, irrespective of grain size, which is reflected by the nanocrystalline and microcrystalline curves approaching one singular strength value. Future work into this fast strain rate region is ongoing [18], to probe material behavior as it pertains to this study with the results leading to a more complete model. 


\subsection{Tensile Testing}

The two experimental methods used to probe a wide range of strain rates are tensile testing and the micro-scratch technique. For the lower strain rates in the range of $1.0^{-5}$ to $1.0^{-1} \mathrm{sec}^{-1}$ tensile testing was the method used to obtain results, while in the higher range of strain rates, $1.0^{0}$ to $1.0^{+3} \mathrm{sec}^{-1}$, the micro-scratch technique was utilized. Figure 1.2 shows the Test Resources ${ }^{\mathrm{TM}}$ table-top universal tensile tester with the serrated grip attachment.

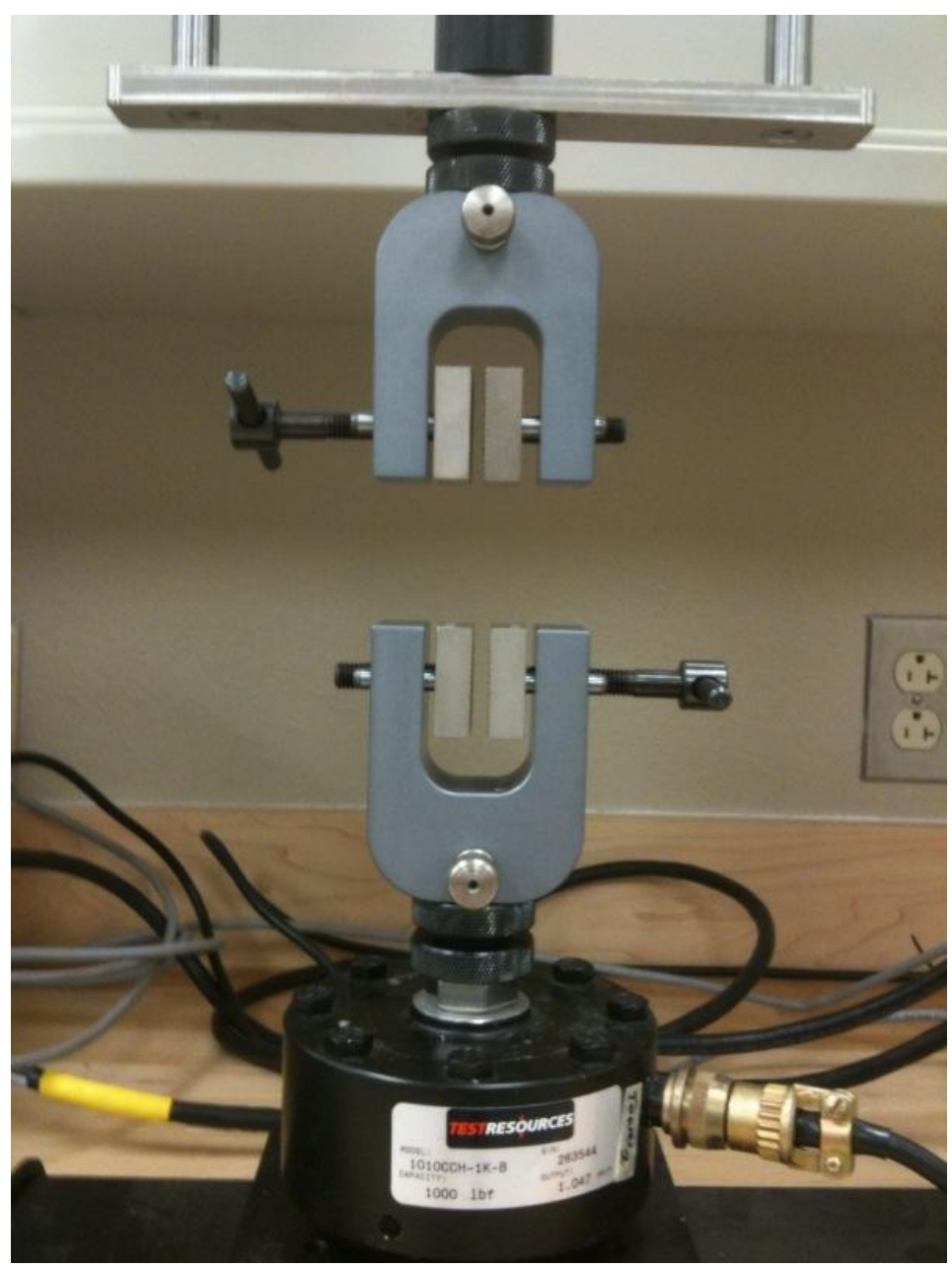

Figure 2.4: Universal Tensile Test Machine 
The annealed and rolled nickel samples where first cut into the "dog-bone" shape using the aluminum die as shown in Figure 1.1. The cross-section area was measured using a micrometer as well as a microscope for verification. The gage length was measured to ensure correct dimensions. Once the samples were cut into the correct test shape, each was inserted individually into the machine and the tensile test was carried out for each strain rate. For the nanocrystalline nickel samples, the gage length was maintained at $10 \mathrm{~mm}$ for each test by ensuring that once the nanocrystalline samples were placed in the machine, the distance between the lower and upper grip mounts remained at $10 \mathrm{~mm}$ before the test began. For each of the given strain-rates, at least 3 samples of each material were tested to ensure reproducible results. Data collected from each test was only utilized if the sample fractured within the gage length, which was visually inspected, as well as the cross-sectional area taken at the point of fracture. In the following Figures 2.5 and 2.6 the annealed and rolled samples are shown after milling, as well as the slightly tapered nanocrystalline strips respectively. 


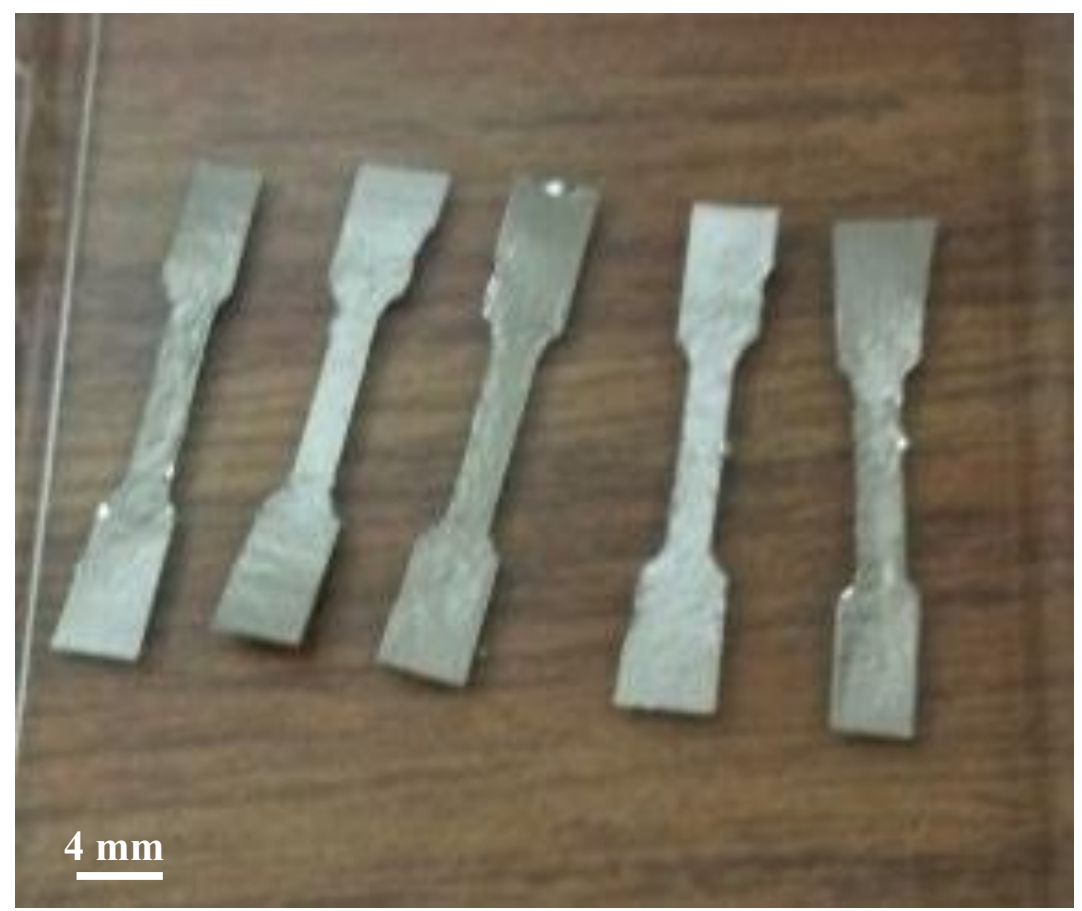

Figure 2.5: Annealed/Rolled Ni Samples after Milling

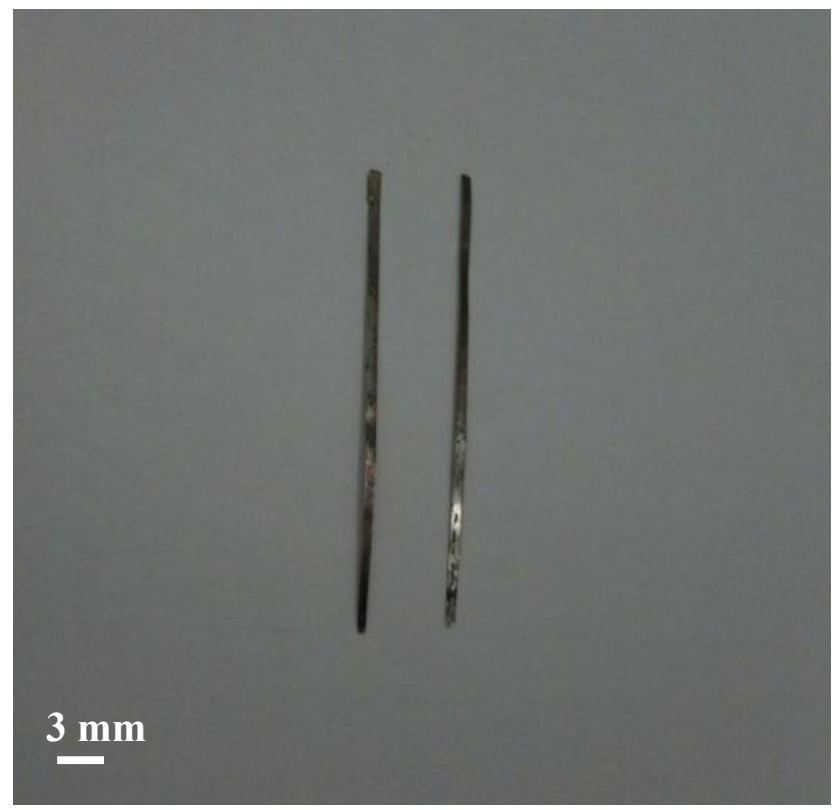

Figure 2.6: Nano-crystalline Ni Samples 
To obtain the broad range of strain rates desired equation 2.3 was used as shown below. Here the $\delta(\mathrm{L})$ term represents the change in linear displacement, while the $\delta(\mathrm{t})$ term represents the time interval. The term $\varepsilon_{e}$ represents the strain rate, and $L_{0}$ represents the initial length, i.e. the gage length of the sample.

$$
\dot{\varepsilon}_{e}=\frac{[\delta(L) / \delta(t)]}{L_{0}}
$$

Using equation 2.3 , the linear displacement $\delta(\mathrm{L})$ and time interval $\delta(\mathrm{t})$, or crosshead velocity, was varied accordingly to achieve a desired rate of loading. The engineering stress $\left(\sigma_{e}\right)$ was calculated by taking the output force values from the tensile test load cell, then dividing by the cross section area of the nickel foil sample. With these values calculated, engineering stress $\left(\sigma_{e}\right)$ vs. engineering strain $\left(\varepsilon_{e}\right)$ curves for each material was plotted, which are shown in Figures 2.7, 2.8, and 2.9, respectively, for annealed, rolled, and nanocrystalline nickel foils. 


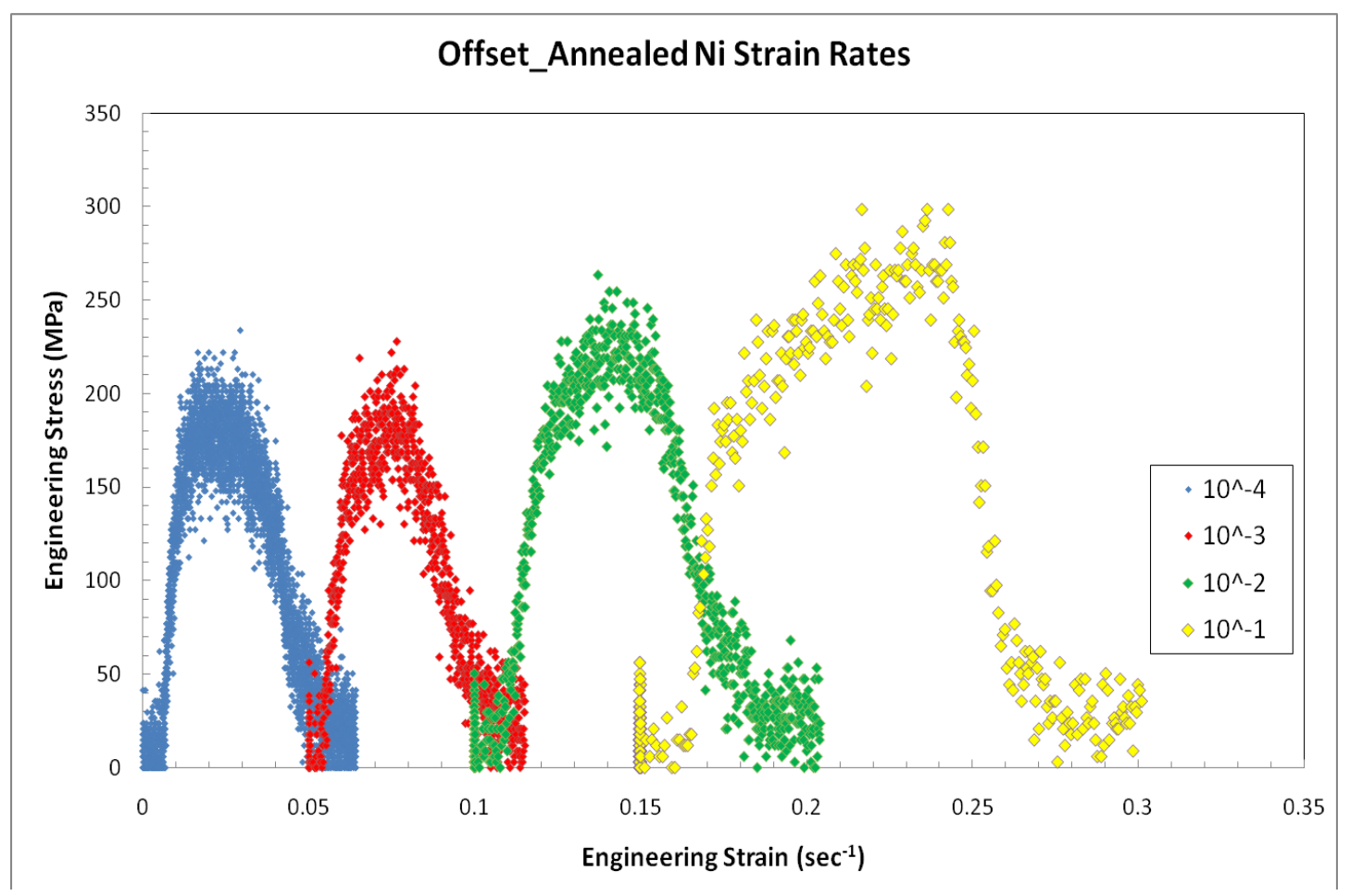

Figure 2.7: Annealed Ni Foil at Four Strain Rates

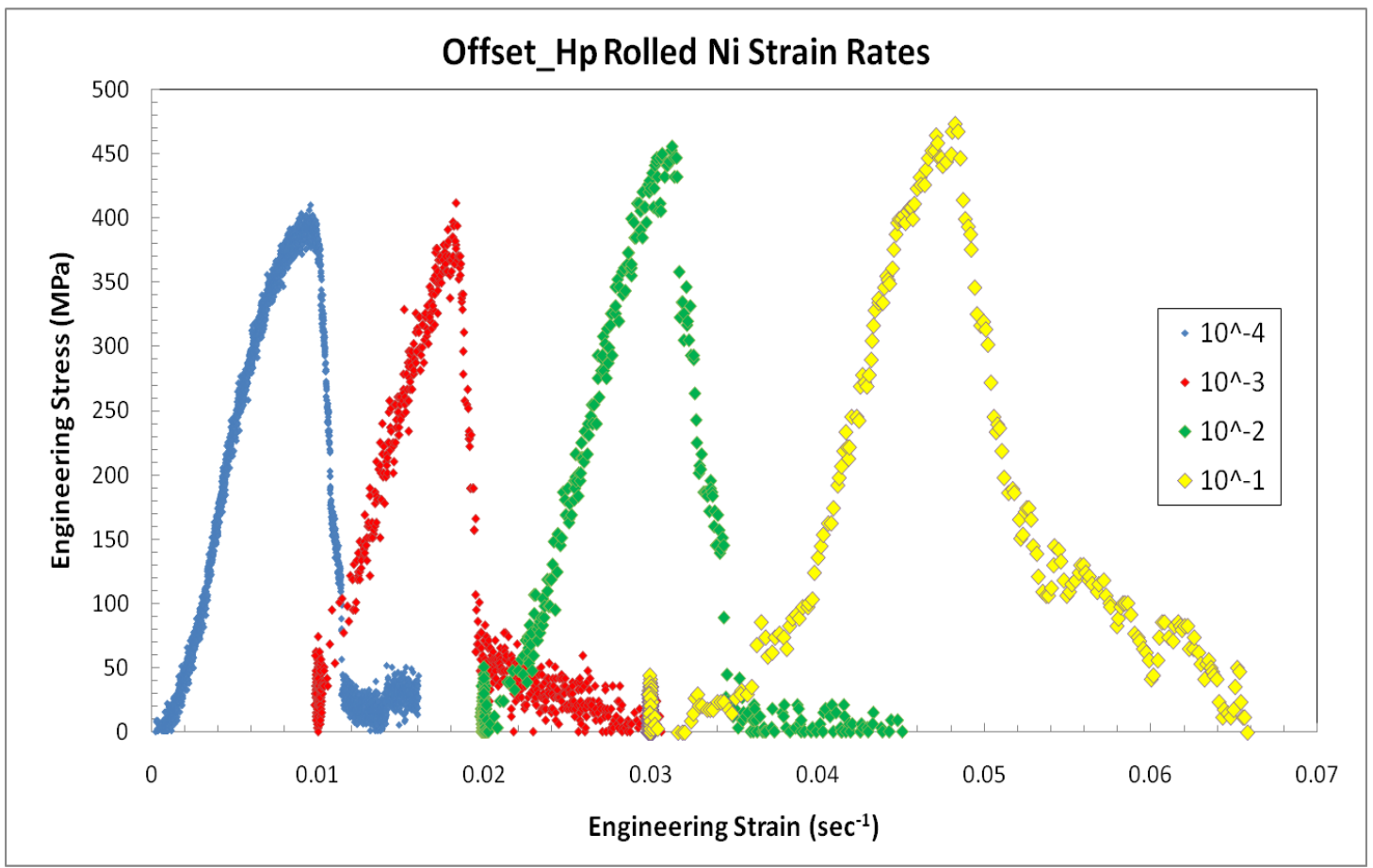

Figure 2.8: Rolled Ni Foil at Four Strain Rates 


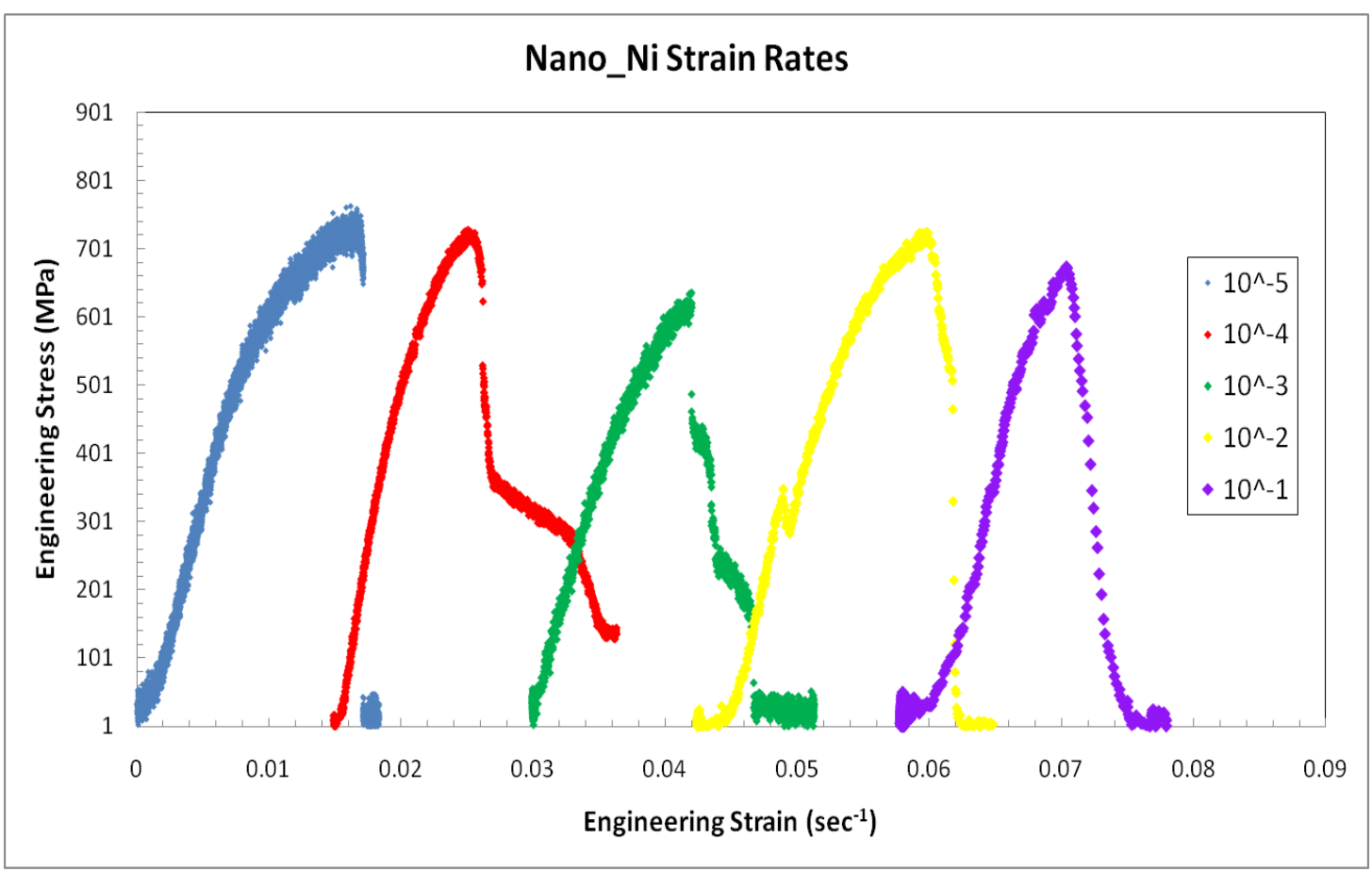

Figure 2.9: Nano Ni Foil at Four Strain Rates

In each of the figures above, an increase in yield strength $\left(\sigma_{y}\right)$ was observed with increasing strain rate $(\dot{\varepsilon})$, as the grain size $\left(h_{g}\right)$ decreased. The yield point for each of the different curves was measured independently. The proportional limit method was used in tandem with a 20 point linear regression line to obtain the slope. This method was used as opposed to the conventional $0.2 \%$ offset method in attempt to avoid capturing strain hardening effects. As shown here and in other works [2], nickel can exhibit a high amount of work hardening. Thus, in some cases using the conventional $0.2 \%$ offset method, the yield point could be located far into this work hardening regime. The result $[3,5]$ could include both strain-rate sensitivity and a fair amount of strain hardening. To try and limit this possible effect, only a proportional limit approach was used in obtaining the yield point of each sample. The elastic 
modulus between all the strain rates appears to remain invariant for each material tested. This result can visually be seen by comparing the slopes at each strain rate. In addition to these plots, graphs were generated which displayed each of the samples at one of the nominal strain rates. This was done in effect to compare each material at one given rate, noticing values for yield strength, ultimate strength, and general shape of the curve. These plots are now shown in Figures 2.10 through 2.13.

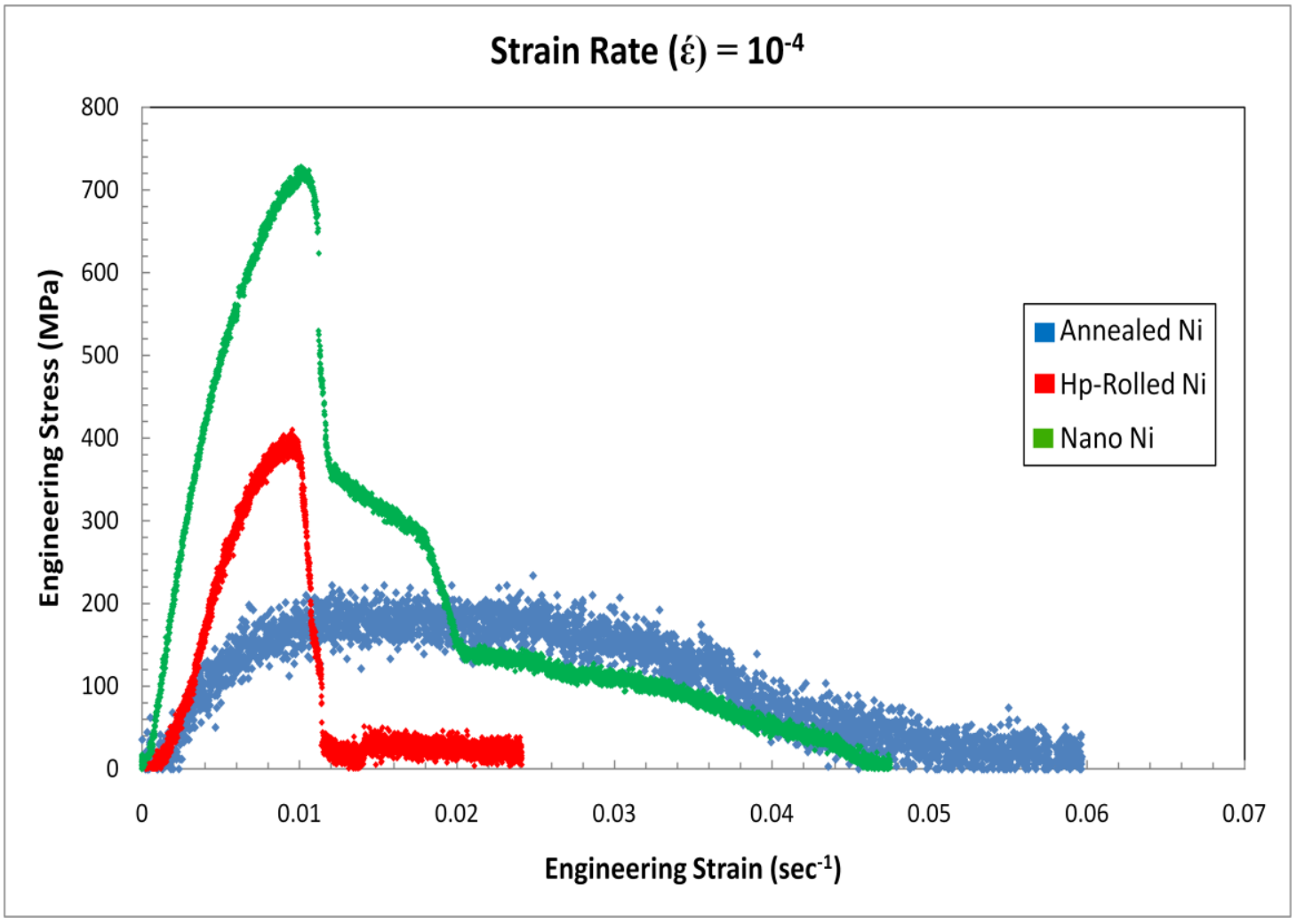

Figure 2.10: Plot of all samples at $\dot{\varepsilon}=10^{-4} \mathrm{sec}^{-1}$ 


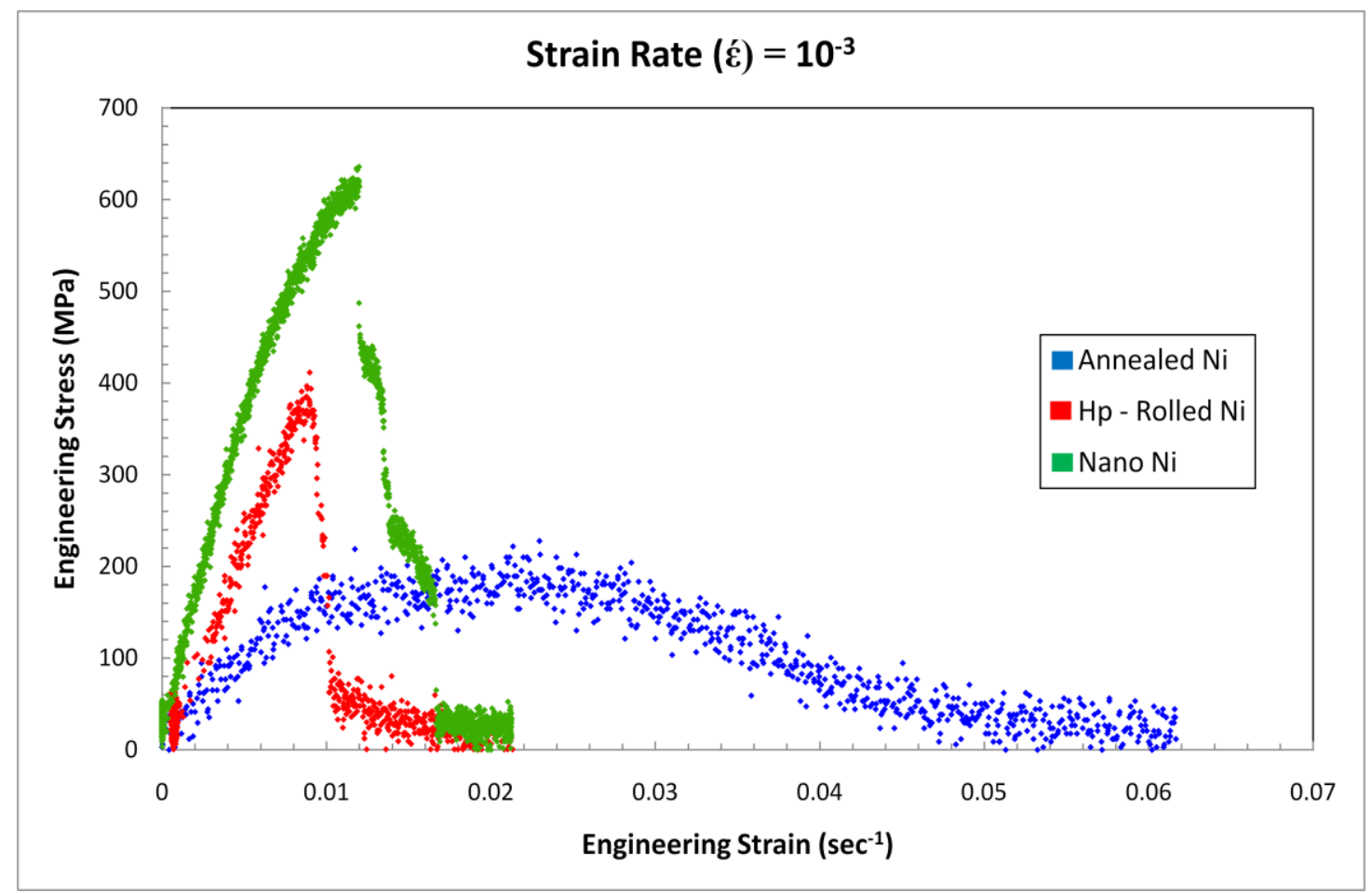

Figure 2.11: Plot of all samples at $\dot{\varepsilon}=10^{-3} \sec ^{-1}$

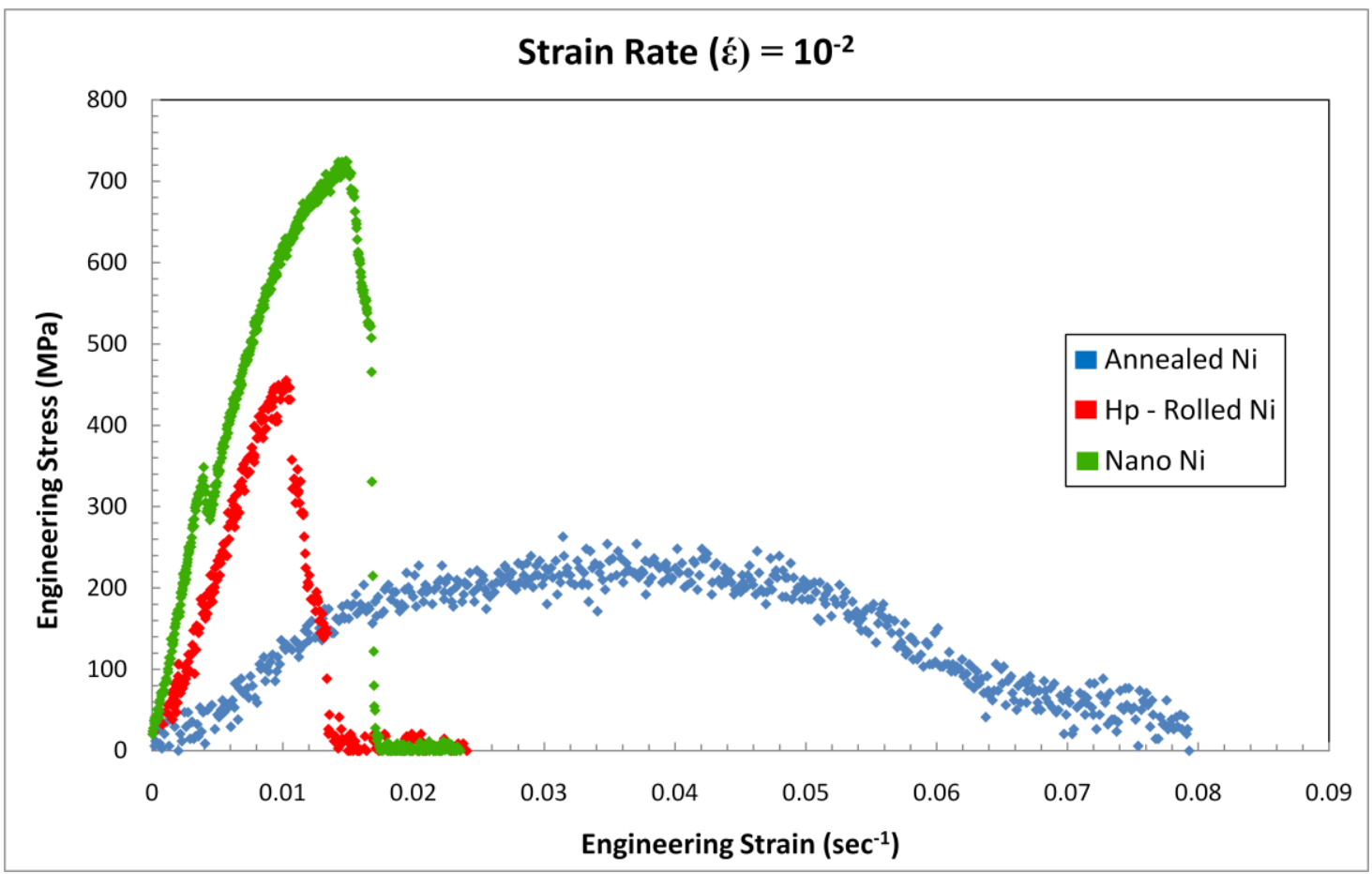

Figure 2.12: Plot of all samples at $\dot{\varepsilon}=10^{-2} \sec ^{-1}$ 


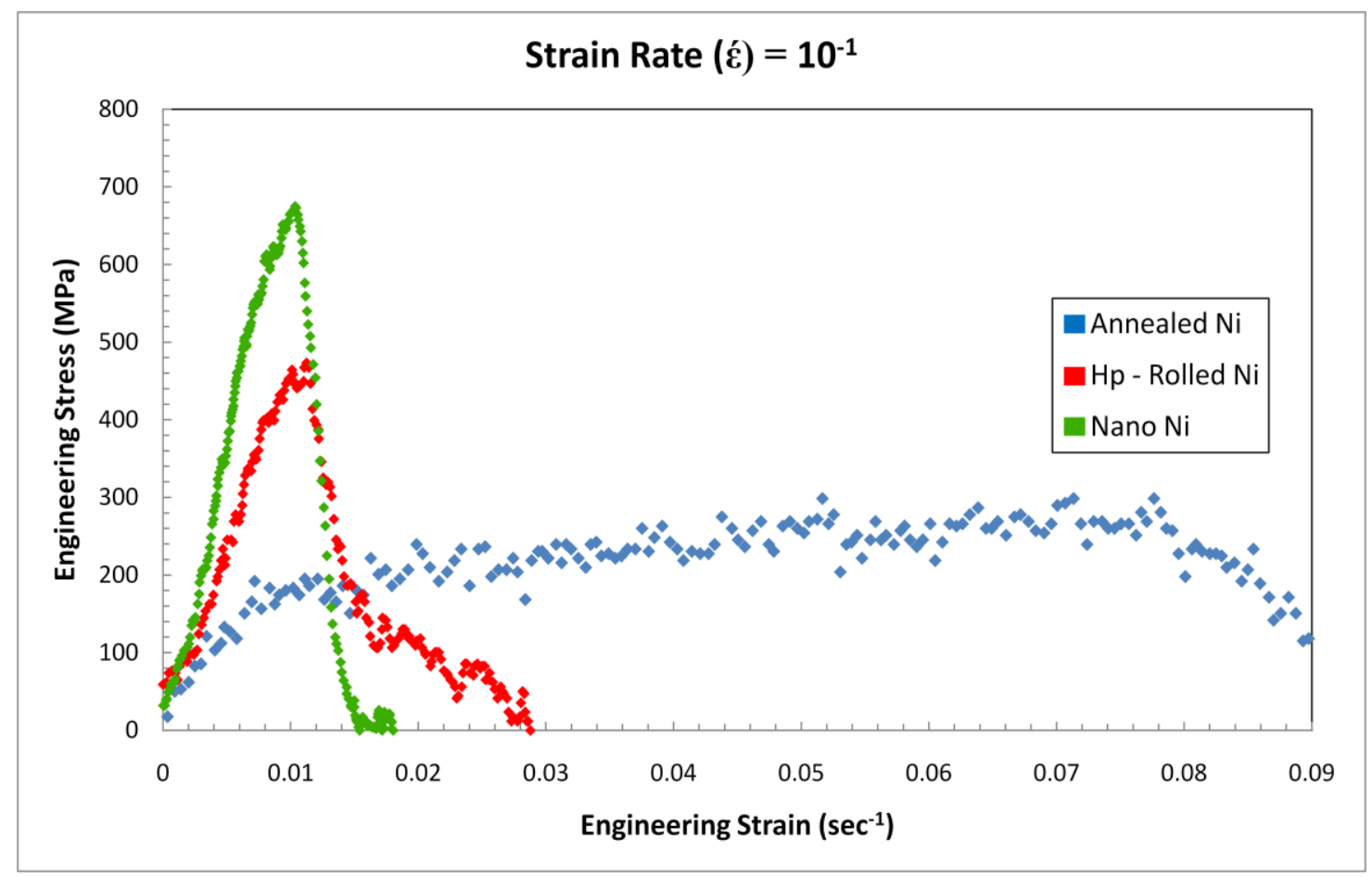

Figure 2.13: Plot of all samples at $\dot{\varepsilon}=10^{-1} \mathrm{sec}^{-1}$ 


\subsection{Micro-scratch Testing}

The second experimental test method used was the micro-scratch technique. The test machine was a CETR Inc. Universal Materials Nano-Tester (UMNT) ${ }^{\mathrm{TM}}$ equipped with a $12.5 \mu \mathrm{m}$ Rockwell indenter tip radius at 60 degree angle. This test rig was used for scratching the surface. The different nickel foil samples were prepared in cross-section as metallographic samples. Figure 2.14 depicts the micro-scratch test rig that was used to conduct these experiments.

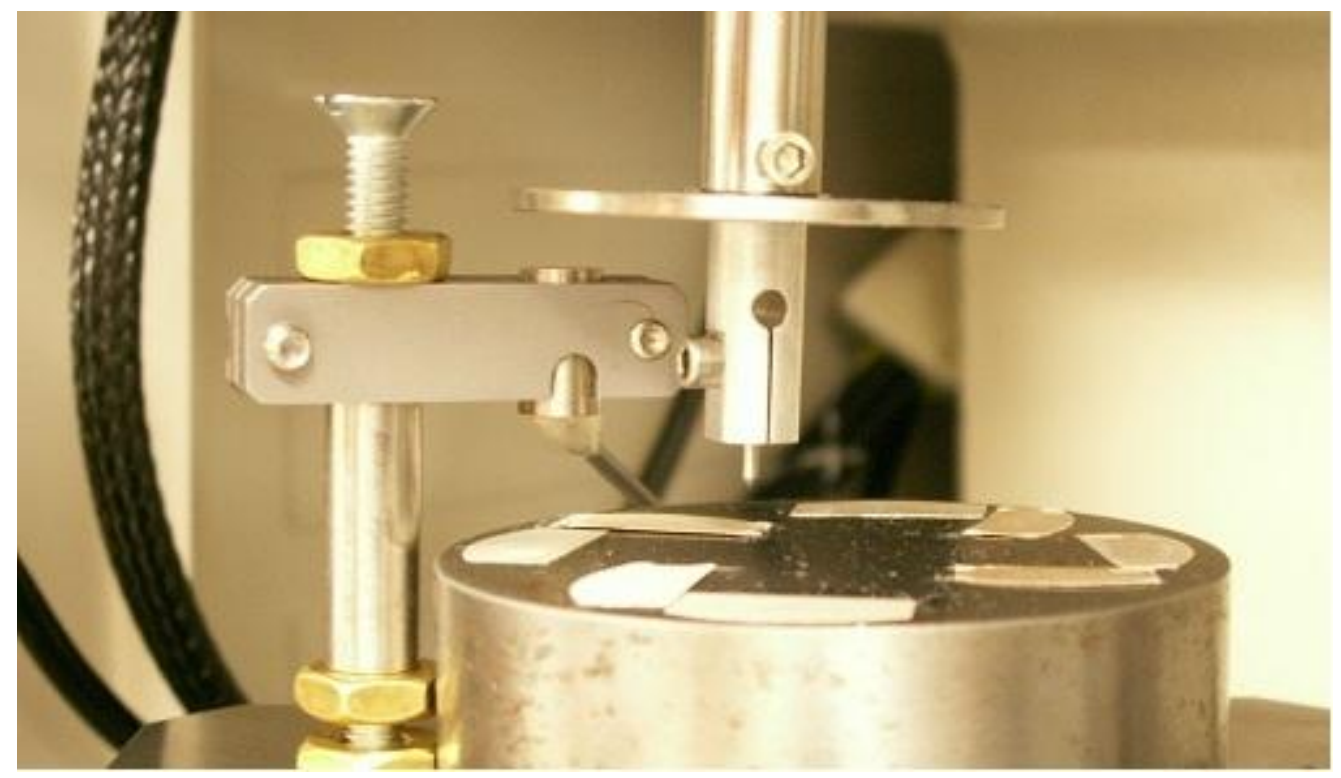

Figure 2.14: Micro-Scratch Test Machine

For all samples tested, a nominal load of $10 \mathrm{gm}(98 \mathrm{mN})$ was held constant normal to the surface. During the actual scratch test, the indenter tip is held constant, while the force plate that the mount is secured to moves in the vertical direction, as well as along the direction of the scratch. To control the load being applied to the surface, a force feedback controller measures force as a function of time. A set of different velocities were used in the scratch test. These velocities include from fastest 
to slowest: $10 \mathrm{~mm} / \mathrm{sec} ; 5 \mathrm{~mm} / \mathrm{sec} ; 3 \mathrm{~mm} / \mathrm{sec} ; 1 \mathrm{~mm} / \mathrm{sec} ; 0.5 \mathrm{~mm} / \mathrm{sec} ; 0.1 \mathrm{~mm} / \mathrm{sec}$; $0.05 \mathrm{~mm} / \mathrm{sec}$; and finally $0.01 \mathrm{~mm} / \mathrm{sec}$. A total of three scratches were done at each given velocity (v) on each of the samples. This was done to determine an accurate statistical average at any given velocity. Figure 2.15 shows the metallographic mounts used in the testing and Figure 2.16 shows a schematic of the test method described above.

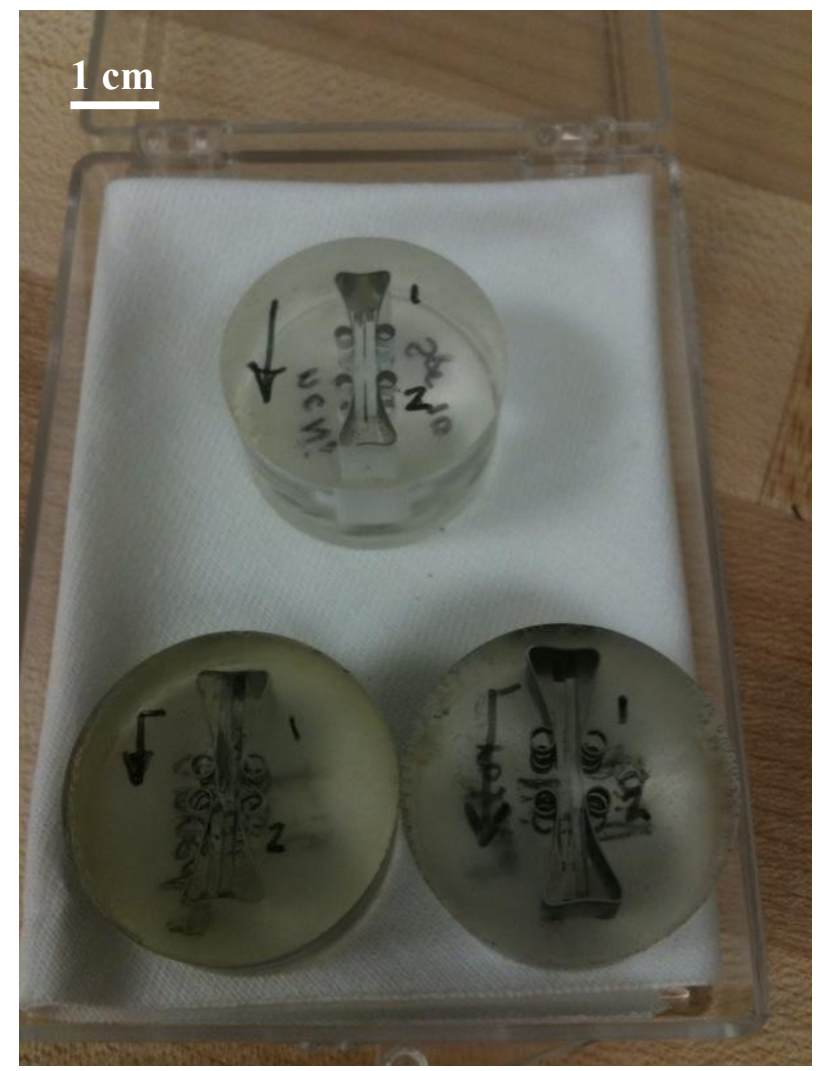

Figure 2.15: Metallographic Mounts

Each of these sample mounts has a nickel foil positioned between two glass slides, which served three purposes: (I) to ensure proper orientation of the crosssection to be used in testing; (II) to hold the sample during the micro-scratch test, to 
prevent "blow out" or a section of the material that gets pushed through the epoxy after the scratch has been made; and (III) to ensure a solid, hard surface for the initial indent into the sample. There is a chance that without the slides, the epoxy could possibly not provide enough resistance for the machine force feedback system to detect initial penetration into the sample. This situation would keep the indenter moving into the sample until eventually enough resistance is met. Then it would proceed to attempt and scratch the sample. At this point, the actual indenter could be several millimeters into the sample already and not at the surface. The glass slides are held together with constant pressure from steel spring clips. The assembly was submerged in a liquid epoxy and placed in a vacuum chamber to remove air bubbles from the epoxy mount. Once the epoxy had set, the samples were cleaned and polished used a grinding wheel. Polishing began with the most abrasive of $15 \mu \mathrm{m}$, then proceeded with a $9 \mu \mathrm{m}$ and $3 \mu \mathrm{m}$ disks, respectively. Finally a diamond powder slurry was used to clean the surface for testing and imaging. 


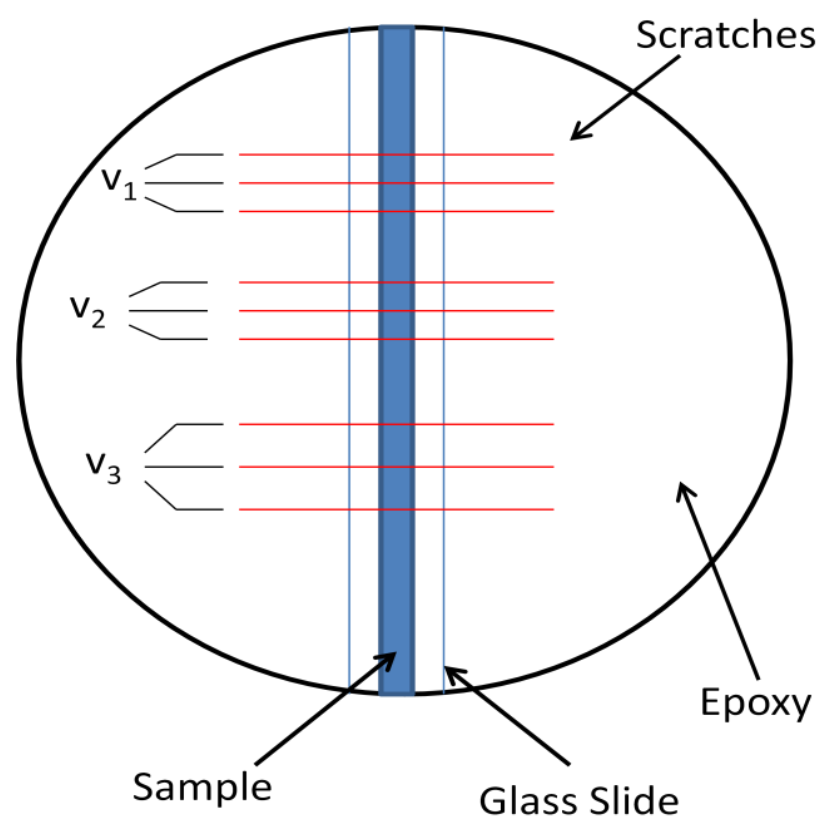

Figure 2.16: Schematic of Fabricated Mounts

Once the testing on the metallographic samples was complete, an optical microscope with camera attachment was used to measure the average width of each scratch. At the very least, four independent measurements were taken at different locations within the scratch to ensure an accurate statistical mean value. A calibration table was provided with the camera to ensure accurate measurements of distance when under high magnification, in this case 40x. Figures 2.17 and 2.18 show the nanocrystalline sample as well as annealed sample after the scratch test had been performed. 

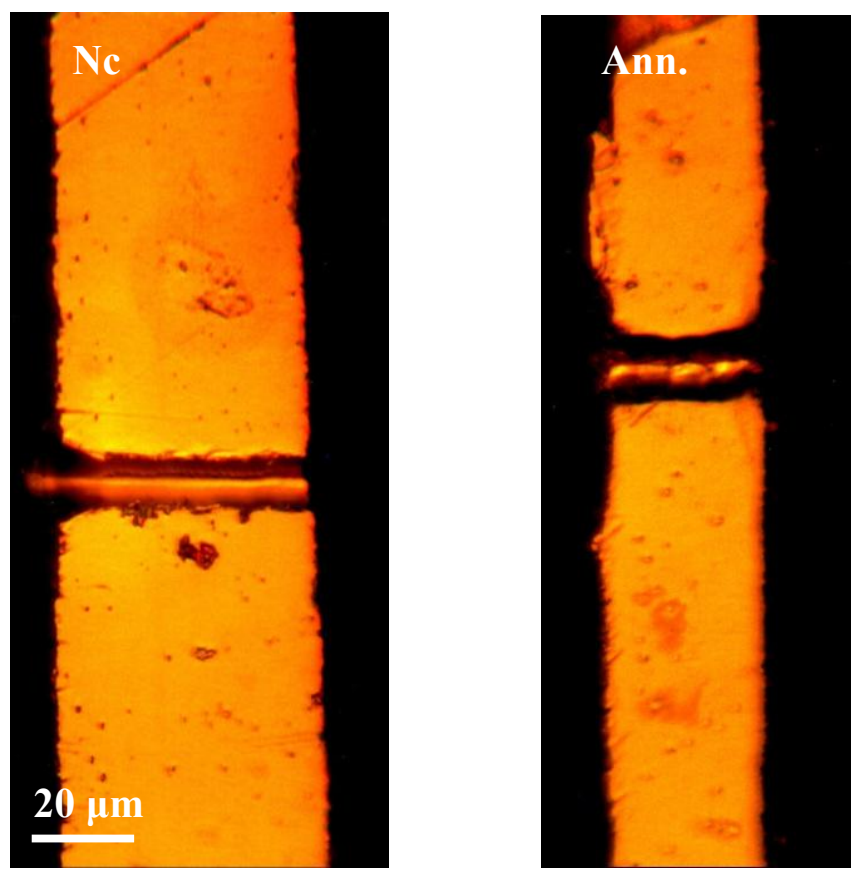

Figure $2.17 \&$ 2.18: Nc and Annealed Ni post scratch

More detail into the results of the scratch testing follow. However, it is important to note that the amount of plastic deformation in each nickel material was within a range of 10 to $20 \mu \mathrm{m}$ for all of the strain rates. This result minimizes variation that may be attributable to strain hardening effects on strength, in addition to the strain-rate sensitivity effect being investigated. The small range of variance for the width of each track throughout the entire length of the scratch for each material ensures a good statistical measure, which can be seen in the Figures 2.17 and 2.18 


\section{CHAPTER III}

\section{EXPERIMENTAL RESULTS}

\subsection{Analysis of Tensile Testing Results}

The values for the strain rate sensitivity exponent $(\mathrm{m})$ were calculated using Microsoft Excel plots for both the tensile testing and micro-scratch data. Figure 3.1 shows the plot which has the yield point for each given material, plotted versus the strain rate on a logarithm scale. The slope of this linear curve, as show in equation 3.1, is the strain rate exponent $(\mathrm{m})$.

$$
m=\frac{\delta \ln (\sigma)}{\delta \ln (\varepsilon)}
$$

Using the values obtained for the engineering stress-strain curves within the tensile testing regime of strain rates, a graph is plotted in Figure 3.1 to measure the change in strain rate sensitivity exponent (m) with each sample.

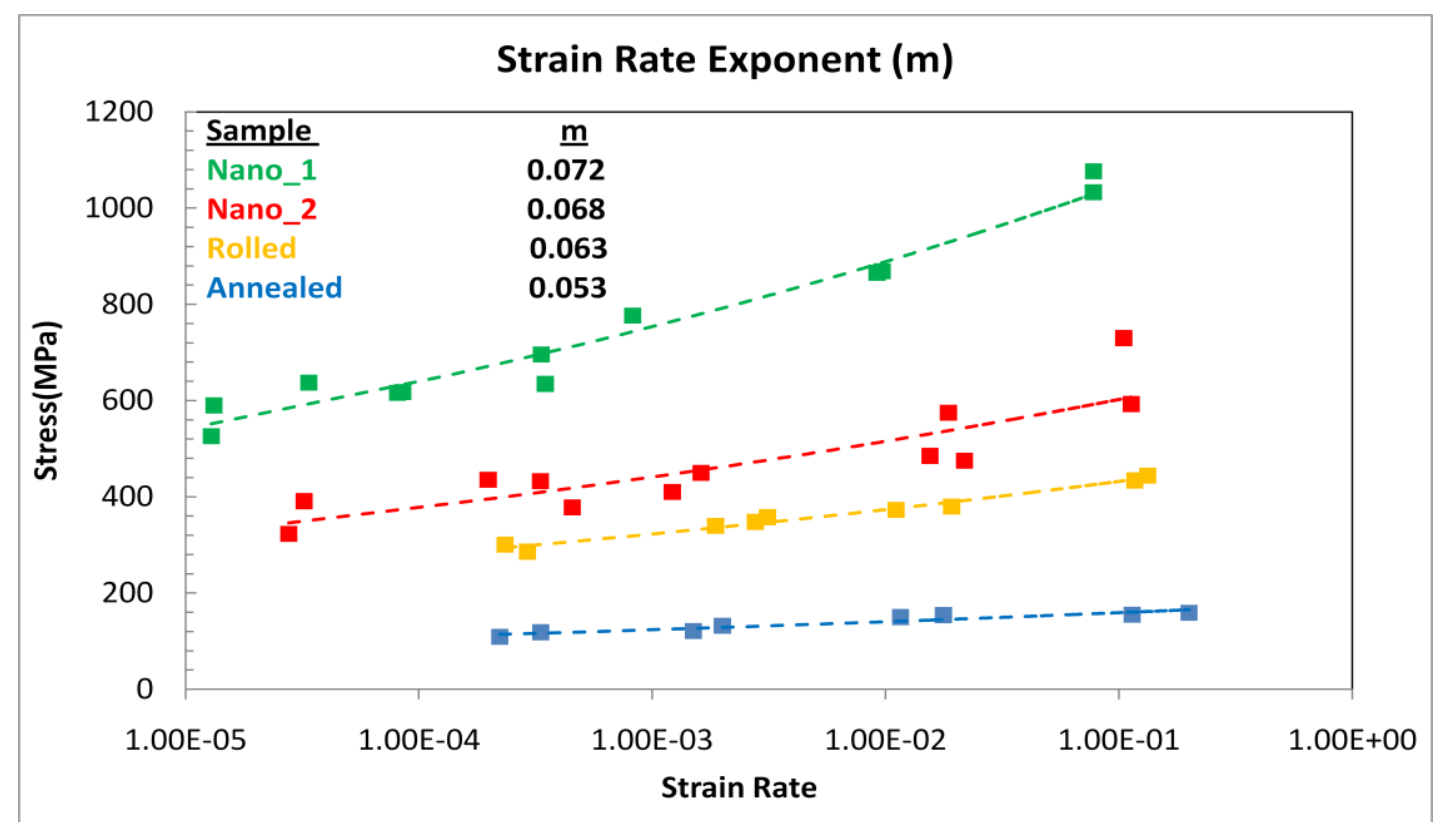

Figure 3.1: Tensile Test Strain-Rate Exponent 
A linear fit has been generated with each set of data points with a trend-line fit displayed. The slope of this trendline, is labeled with the corresponding material. From these Figure 3.1 plots, it is apparent that as grain size $\left(\mathrm{h}_{\mathrm{g}}\right)$ is reduced, the strain rate sensitivity exponent $(\mathrm{m})$ increases. The range of strain rates shown above most closely aligns with region $\mathrm{I}\left(10^{-5}\right.$ to $\left.10^{-1} \mathrm{sec}^{-1}\right)$ and region II $\left(10^{-2}\right.$ to $\left.10^{+2} \mathrm{sec}^{-1}\right)$ that predicts a higher strain rate sensitivity exponent for finer grain materials which is reflected in the tensile test results. From this data, the activation volume $\left(\mathrm{v}^{*}\right)$ can be calculated to give a qualitative approach for evaluating the grain size effect. Activation volume ( $\left.\mathrm{v}^{*}\right)$ is described as the volume needed to activate plastic deformation. Both Wei, et al and Wang, et al studied the temperature dependence and relationship on strain rate sensitivity as well as activation volume of ultrafine grain materials $[8,9,12]$. Equation 3.2 shows the relationship between strain rate sensitivity $(\mathrm{m})$ and activation volume $\left(v^{*}\right)$ as:

$$
m=\frac{k_{b} * T}{\sigma * v^{*}}
$$

Above, $\mathrm{k}_{\mathrm{b}}$ is the Boltzmann constant $\left(1.381 \cdot 10^{-23} \mathrm{~J} \cdot \mathrm{k}^{-1}\right)$, while $\mathrm{T}$ is the temperature in absolute scale (Kelvin), and $\sigma$ is the stress. By equating the expressions for $(\mathrm{m})$ in 3.1 and 3.2, then rearranging the terms provides an expression for describing the activation volume $\left(\mathrm{v}^{*}\right)$ as:

$$
v^{*}=k_{b} \cdot T\left(\frac{\delta \ln (\dot{\varepsilon})}{\delta \sigma}\right)
$$

The rate controlling mechanisms in the plastic deformation of metals can be studied using equation 3.3. Figure 3.2 shows this analysis for the data measured in the 
tensile test experiments for each nickel sample. Equation 3.3 was used to generate the plot of stress $(\sigma)$ versus $\ln$-strain rate $(\dot{\varepsilon})$ in Figure 3.2:

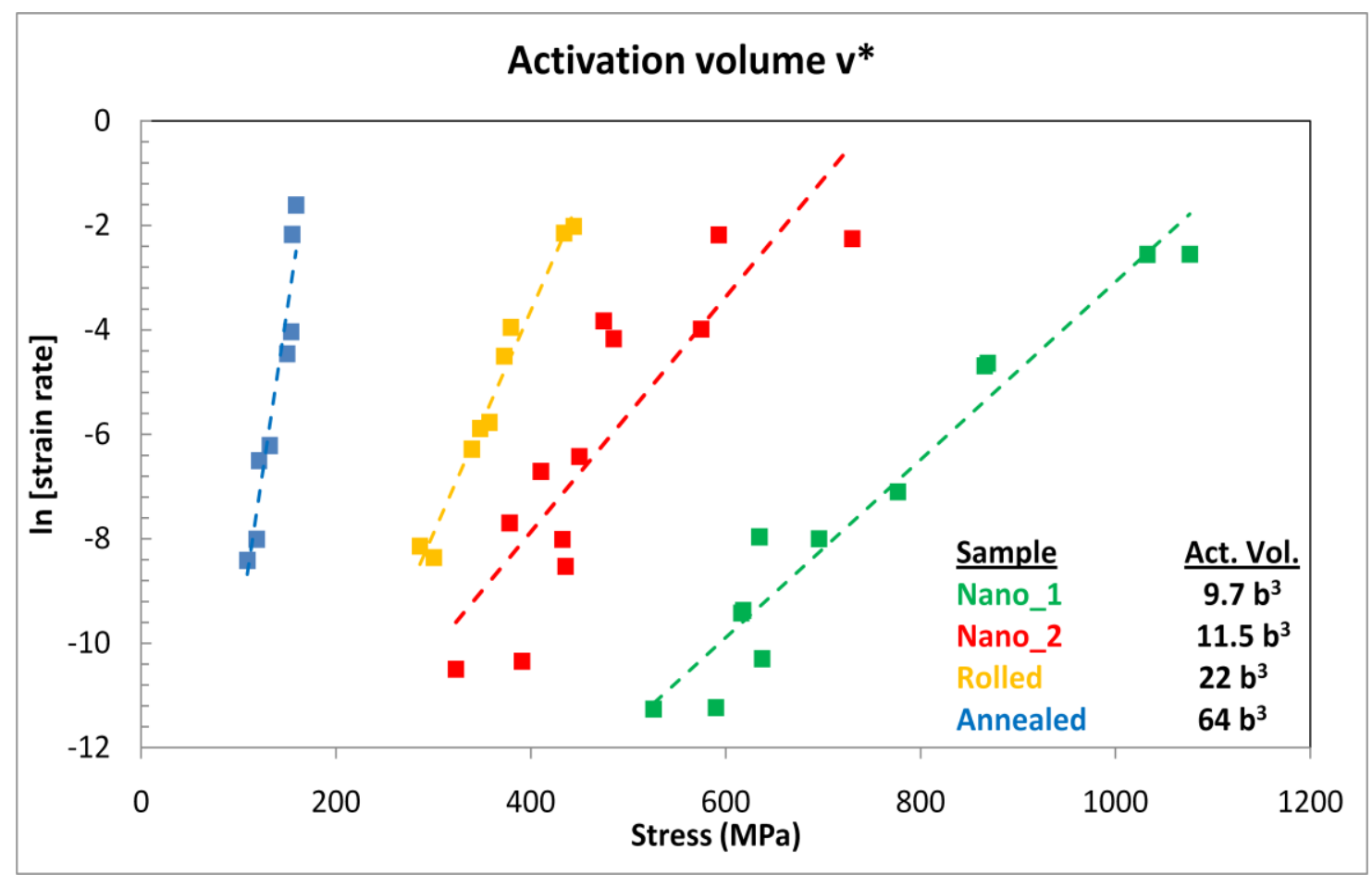

Figure 3.2: Activation Volume

Figure 3.2 shows the general trend of the activation volume for the four nickel samples. The physical observation is that as the grain size decreases, the activation volume $\left(\mathrm{v}^{*}\right)$ is also decreasing, which is reflected by a more gentle slope. The $\mathrm{v}^{*}$ values were calculated from a fit to the slope of the lines. The $v^{*}$ values can be described using the Burger's vector convention with units (b), representing the Burger's vector magnitude $0.2 \mathrm{~nm}$ for nickel. In Table 3.1, the strain-rate sensitivity exponent is shown along with activation volume in terms of the Burger's vector (b) along with an absolute value in cubic nanometers. 


\begin{tabular}{lccc}
\multicolumn{3}{c}{ Table 3.1: Rate Sensitivity Exponent $(\mathbf{m})$ and Activation Volume $\left(\mathbf{v}^{*}\right)$} \\
\hline Sample & $\mathbf{m}$ & $\mathbf{v}^{*}\left(\mathbf{b}^{\mathbf{*}}\right)$ & $\mathbf{v}^{*}\left(\mathbf{n m}^{\mathbf{3}}\right)$ \\
\hline Nano_1 & 0.072 & 9.7 & 0.0776 \\
Nano_2 & 0.068 & 11.5 & 0.092 \\
Rolled & 0.063 & 22.0 & 0.176 \\
Annealed & 0.053 & 47.0 & 0.376 \\
\hline
\end{tabular}

These present values qualitatively agree with similar studies [2,12]. Gu, et al. studied a nickel sample of known grain size $20 \mathrm{~nm}$, and experimentally determined the activation volume to be between $7 b^{3}-14 b^{3}$ using tensile testing and nanoindentation techniques. Physically, the present values are expected. Due to the difference in grain size and dislocation density, a smaller grain size as in the electrodeposited and mechanically rolled samples has less volume available for dislocations, or defects. Due to this smaller volume, the number of defects per grain is smaller compared to the larger grain materials. More energy is required to nucleate and move dislocations through the grain boundary into the next grain. From the present results while still under the Hall-Petch mechanism for strengthening, a higher value for the strain-rate sensitivity exponent $(\mathrm{m})$ is expected [19] with a decreasing value for activation volume $\left(\mathrm{v}^{*}\right)$, which is observed in the results of this study.

An attempt is made, based on the Hall-Petch relationship, to approximate the grain size of each material. In Figure 3.3, this analysis is shown with as subject to the governing equation 2.1. The ultrafine grain size of the smallest nickel sample, known 
from the electrodepostion process, was estimated to be approximately $10 \mathrm{~nm}$ based on the synthesis parameters. The intrinsic friction stress $\left(\sigma_{o}\right)$ value was estimated [20] to be approximately $100 \mathrm{MPa}$. With these two data points, a linear relationship was assumed, and by substituting the yield stress $\left(\sigma_{y}\right)$ into equation 2.1 for each material at each strain rate, a determination for an approximate grain size was made.

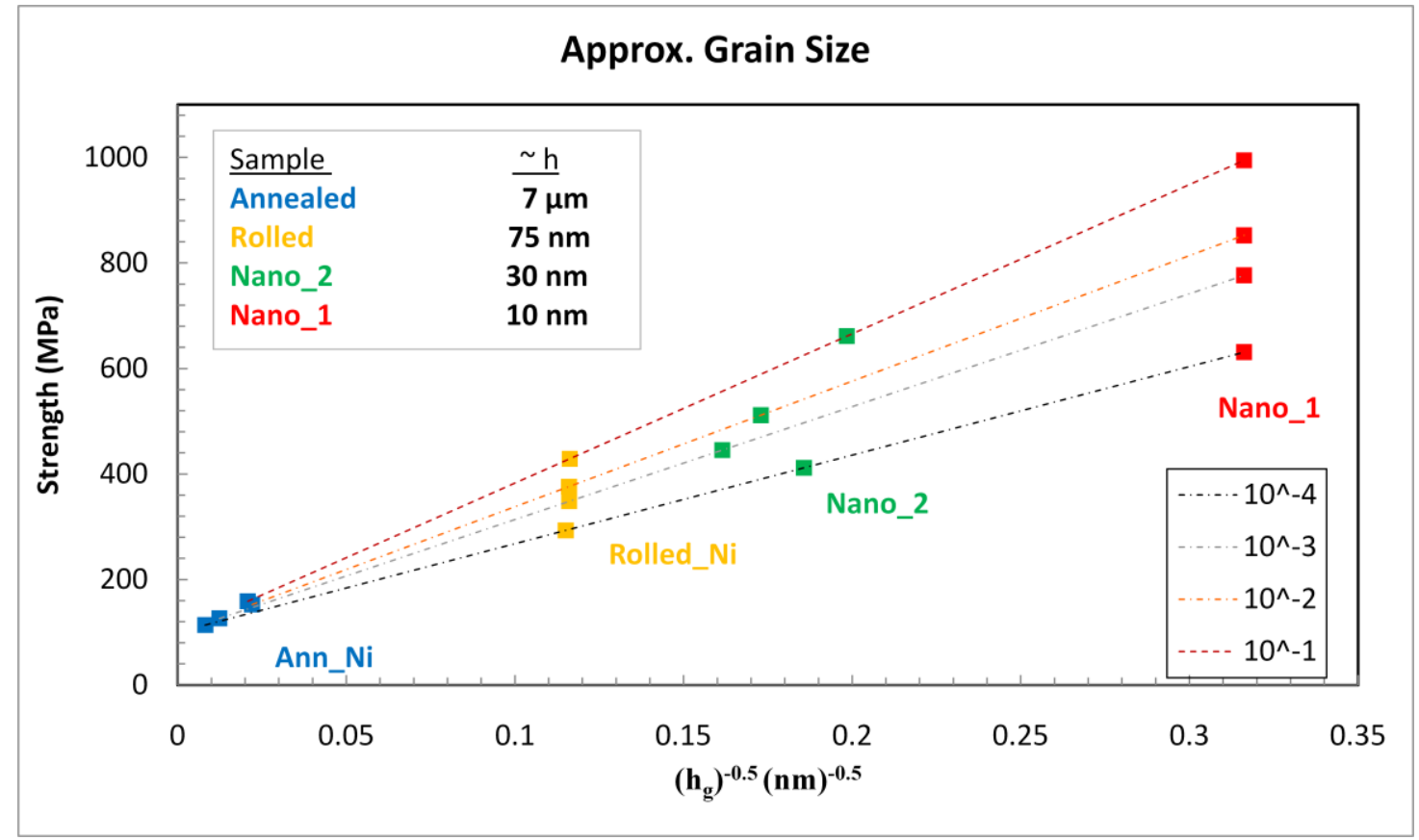

Figure 3.3: Approximate Grain Size

Qualitatively, these Figure 3.3 determined grain size values match up with expectations for grain size. The nano_2 sample was known to be larger than the nano_1 sample due to the electrodepostion process parameters that were used to synthesize the two samples. This present analysis was done to give some idea of grain size, and was not intended to be taken as an absolute value. The Figure 3.3 values represent a reaffirmation of a generally held value in terms of size for the samples. 


\subsection{Analysis of Micro-scratch Results}

Moving into the region II of deformation rate, dynamic indentation method of micro-scratch testing was used, and the strain rate exponent was calculated using equation 3.1. After the scratches were preformed, an optical microscope was used to view and measure the scratches in the sample. As stated above, three scratches were conducted at each velocity to ensure a good statistical measurement. At every scratch, at least four measurements were made to accurately measure the width after the experiment had been preformed. Scratch Hardness $\left(\mathrm{H}_{\mathrm{s}}\right)$ and strain-rate $(\dot{\varepsilon})$ were then calculated [7] using the following two equations:

$$
\begin{aligned}
& H_{S}=\frac{8 \cdot P}{\pi \cdot w^{2}} \\
& \dot{\varepsilon}=\frac{v_{s}}{w}
\end{aligned}
$$

In the above equations, $(\mathrm{P})$ represents the indent load (constant $10 \mathrm{gm}),(\mathrm{w})$ represents the scratch width measured by the optical microscope, and $\mathrm{v}_{\mathrm{s}}$ is the velocity at which the micro-scratch test was carried out (varied from $0.01 \mathrm{~mm} / \mathrm{s}$ to $10 \mathrm{~mm} / \mathrm{s}$ ). Once all the widths had been measured, the scratch hardness $\left(\mathrm{H}_{\mathrm{s}}\right)$ and corresponding strain rates $(\dot{\varepsilon})$ were calculated, and a plot was generated with the values. Overall, the same scale of deformation was seen in at each strain rate per sample. A range of 10 $\mu \mathrm{m}$ to $20 \mu \mathrm{m}$ was measured for the scratch width across the range of strain rates. In Figure 3.4, the strain rate exponent $(\mathrm{m})$ is calculated from the scratch hardness values $\left(\mathrm{H}_{\mathrm{s}}\right)$. 


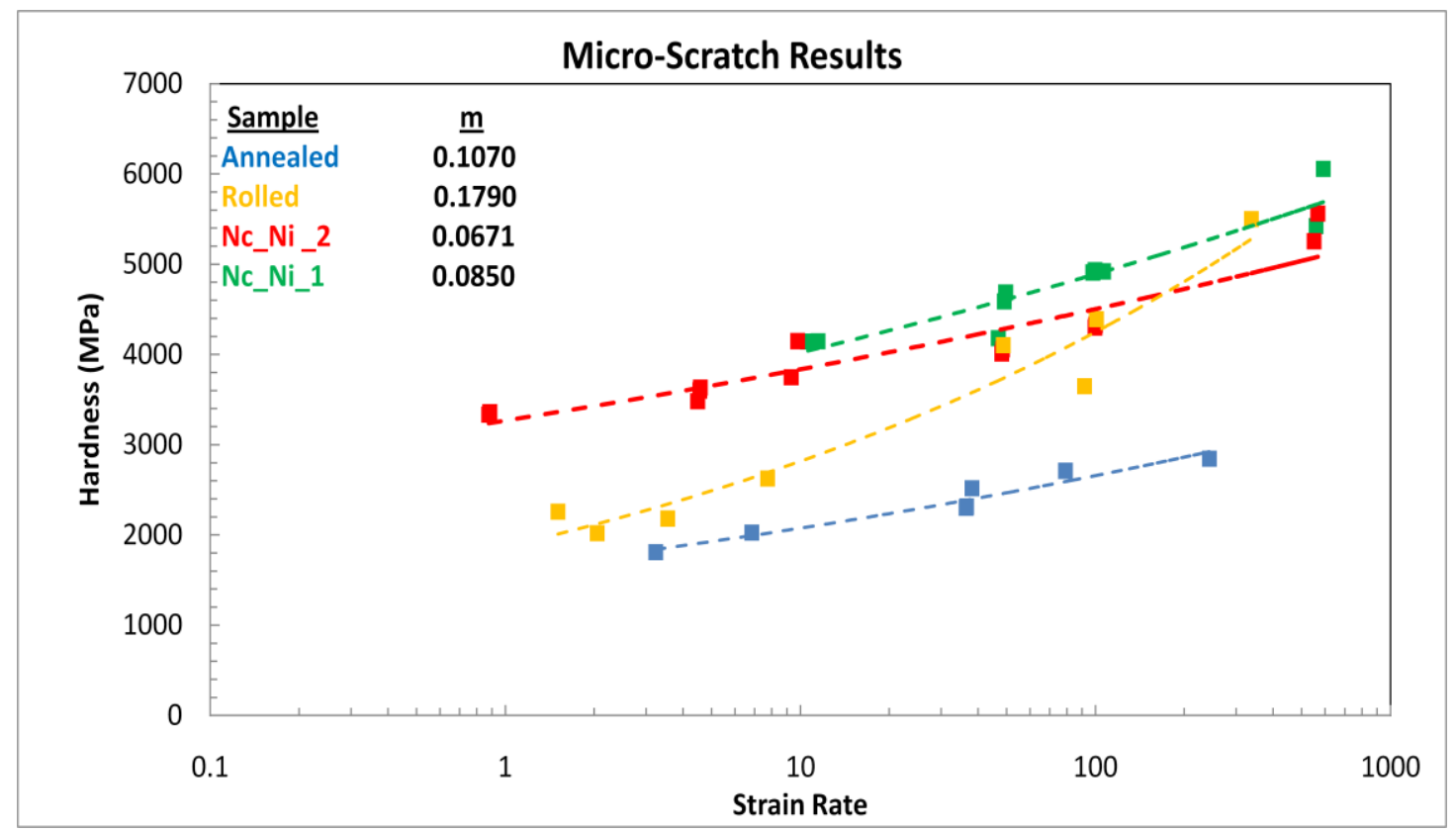

Figure 3.4: Micro-Scratch Strain Rate Exponent

The observation is that the strain rate exponent $(\mathrm{m})$ for both the annealed and rolled nickel samples is higher than the two nano-crystalline samples. The trends show a "take off" for the annealed and the rolled nickel samples, moving past the $10^{2}-10^{3}$ region as the hardness values approach those of the nanocrystalline foils. Although one of the objectives of this study to measure the strain rate sensitivity of different grain size materials has been accomplished, a direct comparison of the tensile test results and micro-scratch results with some overlap in strain rate was also desired. To convert the scratch hardness value into strength, two equations were used [19]:

$$
\begin{aligned}
& \tau=\frac{1}{3} \cdot H_{s} \\
& \sigma=\sqrt{3} \cdot \tau
\end{aligned}
$$


Equation 3.6 is a generalized expression that was probed by Bowden and Tabor [4] which relates scratch hardness to shear stress $(\tau)$. The shear stress can be used to calculate the tensile strength through equation 3.7, which is from the von Mises yield criterion. Substituting the measured values for the scratch hardness $\left(\mathrm{H}_{\mathrm{s}}\right)$ into equation 3.6, and then calculating the strength using equation 3.7 , a plot can generated which includes all of the measured data. A direct comparison of the strainrate sensitivity exponent $(\mathrm{m})$ between test methods can be seen in Figure 3.5.

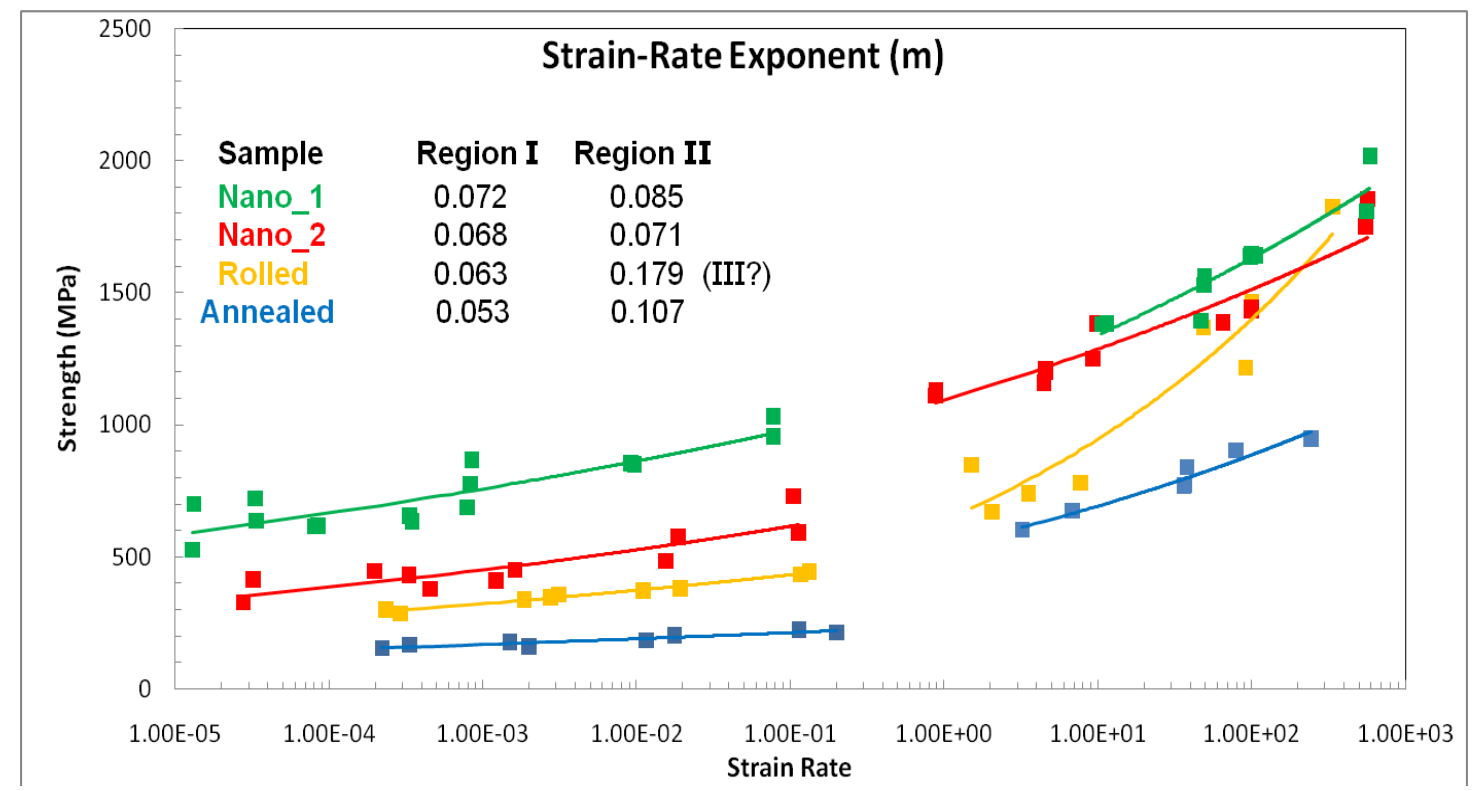

Figure 3.5: Tensile-Micro Comparison

Figure 3.5 represents the direct comparison of the strain-rate sensitivity exponent $(\mathrm{m})$ for both the tensile test results as well as the micro-scratch results. In the tensile test regime, which encompasses both region I and II in terms of the analytical model of Figure 2.3, an increase in strain-rate sensitivity exponent is seen as the grain size is reduced. This trend begins with a value of 0.053 for the annealed sample and reaches an upper limit of 0.072 for the smaller grain sized sample of the two 
nanocrystalline specimens. Moving into the micro-scratch results, which encompass mostly region II and a little of region III, an increase in strain rate sensitivity is seen for all samples from region I values. However, both nanocrystalline samples are increasing at a slower rate than for the two micron sized samples. Although between the two test regions there is a slight discontinuity in strength with a higher strength value moving into the micro-scratch results, this is most likely caused by the tip shape uncertainty as the indenter probes into the material. That is, in equation 3.4 to calculate scratch hardness $\left(\mathrm{H}_{\mathrm{s}}\right)$, an assumed geometric shape for a spherical tip is $\frac{8}{\pi}$. This coefficient could vary, which in turn would change the calculated scratch hardness and strength values. Despite this possible change in the hardness, the trend and strain-rate sensitivity exponent would still remain the same. Therefore, the results obtained are still useful for comparison, even with this potential error in the Figure 3.5 plot. In Table 3.2, the results are summarized with an approximation for grain size included with each nickel sample tested.

Table 3.2: Summary of Strain-Rate Sensitivity Exponent (m) Results

\begin{tabular}{lccc}
\hline Sample & Approx. Grain Size & Region I SRS & Region II SRS \\
\hline Nano_Ni_1 & $\sim 10 \mathrm{~nm}$ & 0.072 & 0.085 \\
Nano_Ni_2 & $\sim 30 \mathrm{~nm}$ & 0.068 & 0.071 \\
Rolled_Ni & $\sim 75 \mathrm{~nm}$ & 0.0633 & 0.179 \\
Annealed_Ni & $\sim 7 \mu \mathrm{m}$ & 0.053 & 0.107 \\
\hline
\end{tabular}


A comparison between the proposed analytical model (shown in Figure 2.3) with the experimental results (shown in Figure 3.5), can be made. Through the regions of strain rate dependent deformation, similar trends in strength are observed between the analytical model originally proposed and the final experimental results. 


\subsection{Discussion}

With results summarized in Table 3.2, the two postulates of this research effort can be effectively addressed. The first being the direct comparison of the two mechanical testing methods of tensile testing and the dynamic indentation method of micro-scratch testing. The second being as to what effect grain size has on the strainrate sensitivity of strength over a wide range of strain rates. After both test methods were performed, the two methods were in fact shown to be comparable across a very large range of strain-rates as achievable in this study. From the tensile testing, the largest change in strain-rate sensitivity was observed to be from the two nanocrystalline samples at 0.072 and 0.068 respectively, followed by the mechanically rolled sample and fully annealed sample at 0.063 and 0.053 respectively. From the literature these results were expected due to the driving mechanism of deformation in the first and second regions as based on solution chemistry and dislocation behavior as outline in the models section above $[1,2,3]$. When comparing the activation volume $\left(\mathrm{v}^{*}\right)$ with the rate sensitivity exponent $(\mathrm{m})$ and with grain size $\left(\mathrm{h}_{\mathrm{g}}\right)$, a relation can be seen that as the grain size $\left(h_{\mathrm{g}}\right)$ decreases the activation volume $\left(\mathrm{v}^{*}\right)$ also falls while the rate sensitivity exponent $(\mathrm{m})$ increases. These results have been seen previously $[1,2,3,8,12]$ but only at strain rates comparable with region I and partially region II. Moving on into the faster strain rate regions (II and III), the strain rate sensitivity of strength is increasing for each of the materials present. However, for the larger grain materials, the increase in $\mathrm{m}$ with increasing $\dot{\varepsilon}$ occurs more rapidly. For the annealed and rolled sample, a rate sensitivity $\mathrm{m}$ value of 0.107 and 0.179 are observed respectively, while for the two electrodeposited samples, $\mathrm{m}$ values of .085 and .071 are 
measured. The two larger grain samples display a larger value for rate sensitivity than the two smaller sized samples which supports the notion of a convergence to a maximum strength well into the high strain rate region (III). A variation between the annealed and mechanically rolled sample is also seen. The rolled sample behavior is observed to show a region of extreme "take off" near the end of strain rate spectrum. More research is needed to effectively answer what deformation mechanism occurs in this region. However, it is generally postulated $[1,7]$ that the highly deformed material during processing is the main cause of this tremendous increase in strain-rate sensitivity in region III. Dislocation density, dislocation nucleation, grain boundary sliding and rotation, are all shown to be mechanism features for deformation in the faster strain-rate ranges. In this study, coarse and ultrafine nickel have a different sensitivity to these deformation features than nano-sized nickel grains in terms of strain-rate sensitivity of strength. Further x-ray diffraction and microstructure imaging are greatly desired to be able to obtain a clear view of the grain structures that accompany deformation of each experimental method, as well as to obtain accurate values for the grain size of each sample. 


\section{Chapter IV}

\section{CONCLUSions}

\subsection{Final Summary}

The tensile testing and micro-scratch testing methods can be directly compared, and the strain-rate sensitivity can be evaluated for a given material using each experimental method. In general, strain-rate sensitivity of strength increases as: grain size decreases; with increasing strain rate from $10^{-5}$ to $10^{+3}$ (Regions I, II, and possibly III); and finally, more slowly for nanocrystalline nickel than for microcrystalline nickel. Observed as well, is a qualitative agreement between an accompanying proposed analytic model and the final experimental results. Through calculating the activation volume as well, and comparison to the rate sensitivity exponent, additional insight is shed on the controlling mechanisms through a broad range of deformation rates. 


\subsection{Future Investigations}

While the trends are shown for Region I and Region II, the detailed behavior in Region III remains to be probed. For future work, exploring the very fast strain rate region would help give a much more complete model for the behavior of micro/nanocrystalline nickel. This high strain rate regime could be explored using split- Hopkinson on pressure bar tests as well as nano-scratch testing, provided proper sample preparation is conducted. Two phase materials are also a point of interest such as those that are formed in high deformation processes as friction stir welding. A sample that has undergone this kind of welding deformation can then undergo microscratch testing for which the mechanical properties of each deformation zone can be measured independently. Micro-scratch testing provides an immense benefit versus normal indentation techniques as independent constituent phases or zones do not have to be identified specifically to be mechanically tested, but rather the entire resulting structure is probed without need for sectional positioning [10]. Finally, if some possible hardware modifications could be achieved, then it is theoretically possible to use just micro-scratch testing to span a very wide range of deformation rate as examined in this study. This method provides a huge advantage in the ability to test one sample, and obtain such a wide range of data from slower to faster strain rates. Also, because micro-scratch testing takes up a very small area, a very small amount of material could be used to gather the material properties as they relate to this study. Conversely, it would be necessary to manufacture multiple tensile test bars, and conduct engineering stress-strain calculations followed by determination of the 
location for the yield point whereas only the measurement of the scratch width and hardness would be needed at each strain-rate of deformation. 


\section{REFERENCES}

[1] B.L. Boyce, M. F. Dillmore."The dynamic tensile behavior of tough, ultrahighstrength steels at strain-rates from $0.0002 \mathrm{sec}^{-1}$ to $200 \mathrm{sec}^{-1 "}$. Elsevier: International Journal of Impact Engineering, 30 (2009) pp. 263-271.

[2] C.D. Gu, J.S. Lian, Q. Jiang, and W.T. Zheng, "Experimental and modeling investigations on strain rate sensitivity of an electrodeposited $20 \mathrm{~nm}$ grain sized $\mathrm{Ni}$ ”, Journal of Physics D: Applied Physics, 40 (2007) 7440-7446.

[3] Cavaliere, P. "Strain rate sensitivity of ultra-fine and nanocrystaline metals and alloys". Elsevier: Physica, B 403 (2008) pp. 569-575.

[4] F P Bowden and D Tabor. "Friction, lubrication and wear: a survey of work during the last decade", Journal of Applied Physics, 17 (1966) 1521.

[5] A.F. Jankowski and H.S. Tanvir Ahmed, "Plasticity of nanocrystalline nanolaminates: strain-rate sensitivity", $15^{\text {th }}$ International Symposium on Plasticity, ed. Akhtar S. Khan, Proceedings Plasticity 09 (NEAT Press, 2009) 403-405.

[6] J. Harding, 'The effect of high strain rate on material properties', Materials at High Strain Rates, T.Z. Blazynsky (ed.), Elsevier Applied Science, Amsterdam (1987) pp 133.

[7] L.O. Nyakiti and A.F. Jankowski, "Characterization of strain-rate sensitivity and grain boundary structure in nanocrystalline gold-copper alloys", Metallurgical and Materials Transactions A 41 (2010) 838-847.

[8] Q. Wei, S. Cheng, K.T. Ramesh, and E. Ma, "Effect of nanocrystalline and ultrafine grain sizes on the strain rate sensitivity and activation volume: fcc versus bcc metals", Materials Science and Engineering A 381 (2004) 71-79.

[9] Q. Wei, D. Jia, K.T. Ramesh, E. Ma, "Evolution and microstructure of shear bands in nanostructured Fe", Applied Physics Letters 81 (2002) 1240-1242. 
[10] S. Swaminathan, K. Oh-ishi, A.P. Zhilyaev, C.B. Fuller, B.London, M.W. Mahoney, T.R. Mcnelley. "Peak Stir Zone Temperatures during Friction Stir Processing". Metallurgical and Materials Transactions , 41 A (2010) pp. 631-640.

[11] X.F. Zhang, T. Fujita, D.Pan, J.S. Yu, T.Sakurai, M.W. Chen. (2010). Elsevier: Materials Science and Engineering, A 527 pp. 2297-2304.

[12] Y.M. Wang, A.V. Hamza, E. Ma ,"Temperature-dependent strain rate sensitivity and activation volume of nanocrystalline Ni”, Acta Materialia 54 (2006) 2715-2726.

[13] A.F. Jankowski, "Modeling Nanocrystalline Grain Growth during the Pulsed Electrodeposition of Gold-Copper”, Electrochemical Society Transactions 1 (12) (2006) 1-9.

[14] A.F. Jankowski, C.K. Saw, J.F. Harper, R.F. Vallier, J.L. Ferreira, and J.P. Hayes, "Nanocrystalline Grain Size Effects in Gold-Copper Electrodeposits", Thin Solid Films 494 (2006) 268-273.

[15] M. Dao, L. Lu, R.J. Asaro, J.T.M. De Hosson, and E. Ma, "Toward a quantitative understanding of mechanical behavior of nanocrystalline metals", Acta Materialia, 55 (2007) 4041-4065.

[16] R.W. Armstrong, S.M. Walley, 'High strain rate properties of metals and alloys', International Materials Reviews 53 (2008) 105-128.

[17] Dean L. Preston, Davis L. Tonks, and Duane C. Wallace, "Model of plastic deformation for extreme loading conditions”, Journal of Applied Physics 93 (2003) 211-220.

[18] B.A. Remington, H.-S. Park, S.T. Prisbrey, S.M. Pollaine, R.M. Cavallo, R.E. Rudd, K.T. Lorenz, R.C. Becker, J.V. Bernier, N.R. Barton, A. Arsenlis, S.G. Glendinning, A.V. Hamza, D.W. Swift, A.F. Jankowski, and M.A. Meyers, "Progress towards materials science above $1000 \mathrm{GPa}$ (10 Mbar) on the NIF laser", DYMAT 2009 (2009) 3-9. 
[19] A.F. Jankowski and L.O. Nyakiti, "Anomalies in Hall-Petch Strengthening for Nanocrystalline Au-Cu Alloys Below $10 \mathrm{~nm}$ Grain Size”, Surface and Coatings Technology (in press) 10.1016 (2010) 106.

[20] Hall, E.O 1951, "The deformation and ageing of mild steel: III Discussion of results", Proceedings of the Physical Society, B 64 747-753.

[21] W.L. Mankins and S. Lamb, "Nickel and Nickel Alloys" in Properties and Selection: Nonferrous Alloys and Special Purpose Materials, ASM Handbook Volume 2 (ASM International, Metals Park, 1990, $3^{\text {rd }}$ edition) pp 428-445.

[22] Petch, N.J. 1953, "The cleavage strength of polycrystals", Iron and Steel Institute 174 (1961) 25-28. 


\section{APPENDiX A}

\section{SRS AND ACTIVATION Volume CALCUlations}

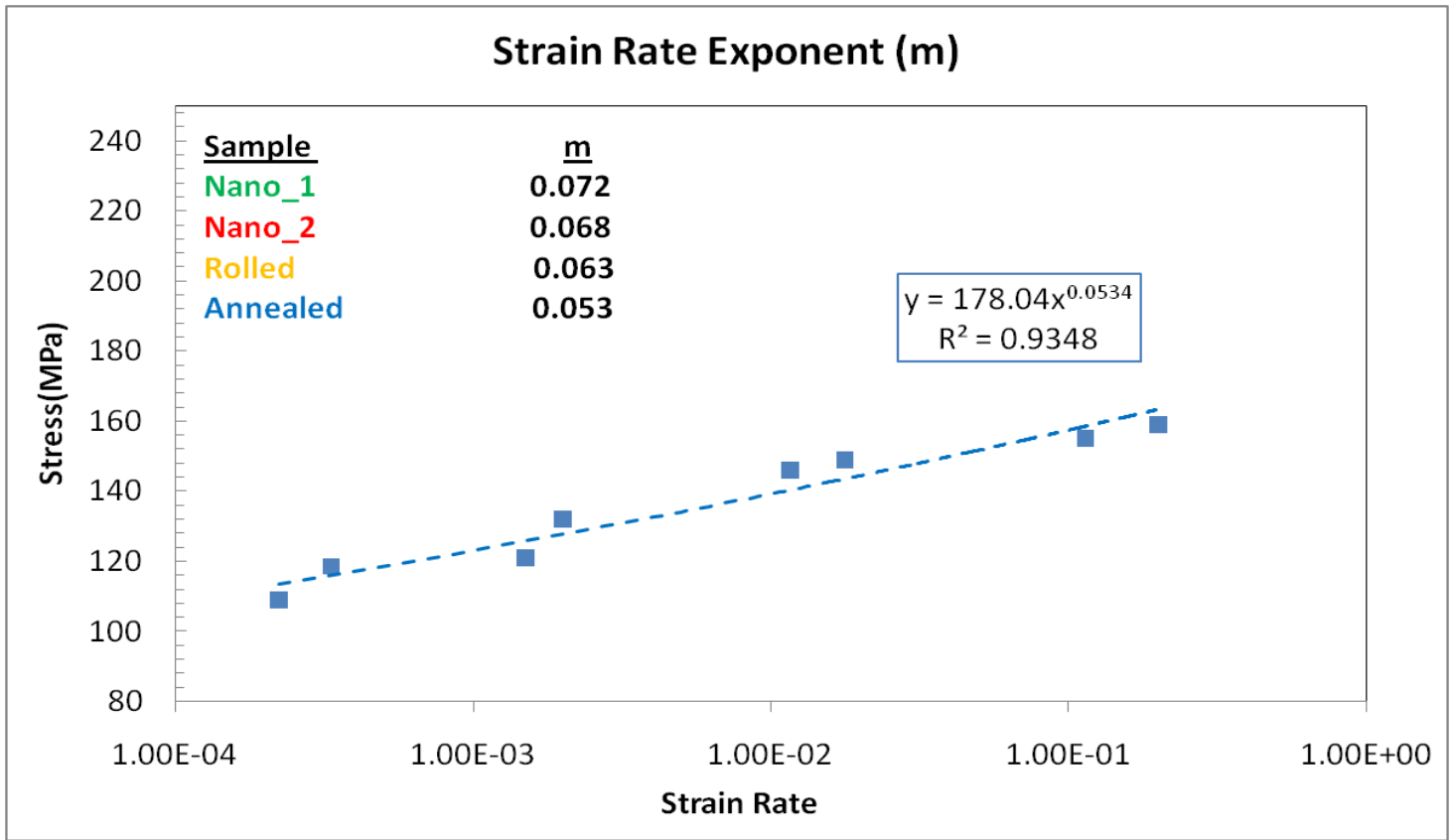

Figure A.1: SRS Exponent of Annealed Sample - Tensile Testing

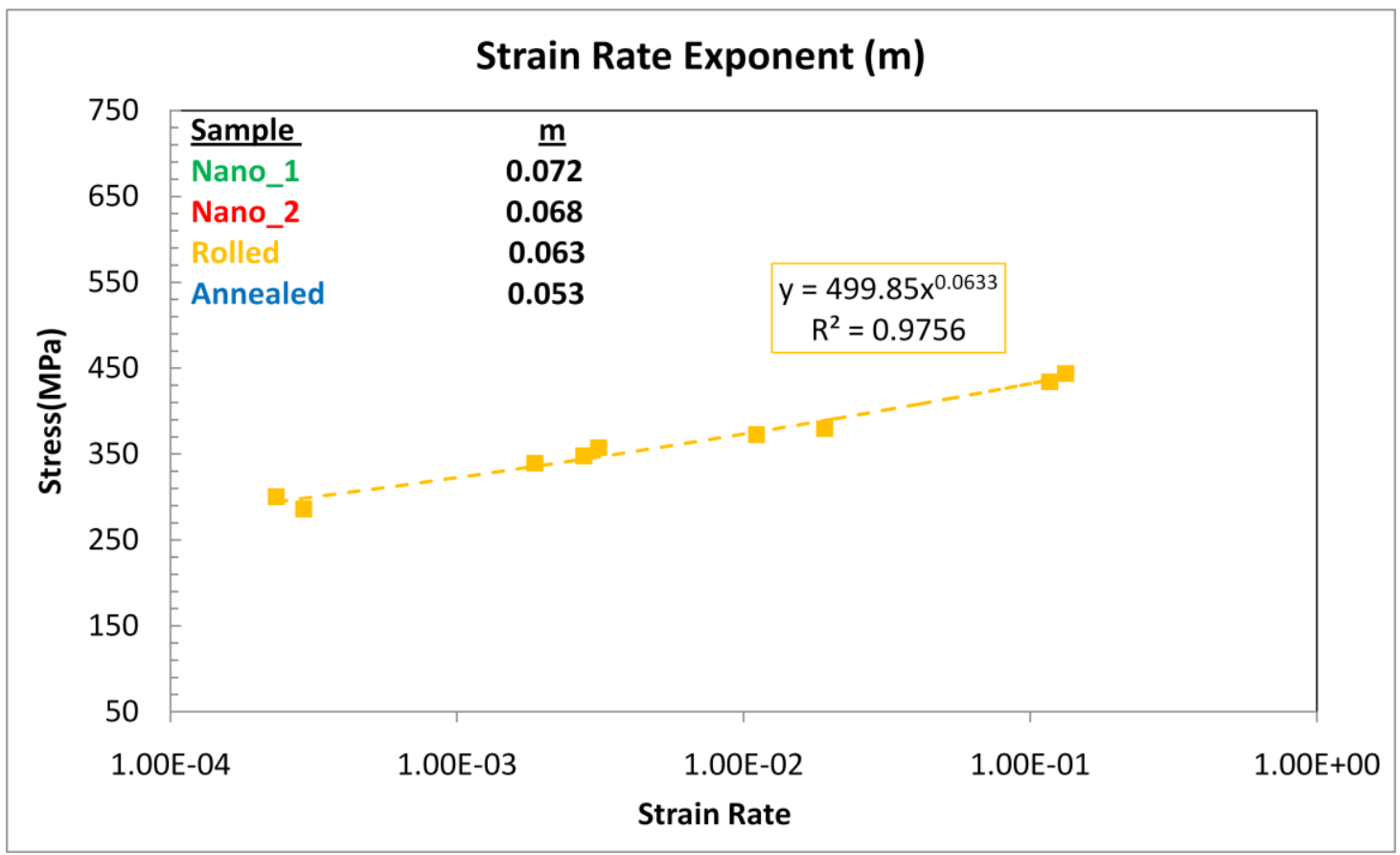

Figure A.2: SRS Exponent of Rolled Sample - Tensile Testing 


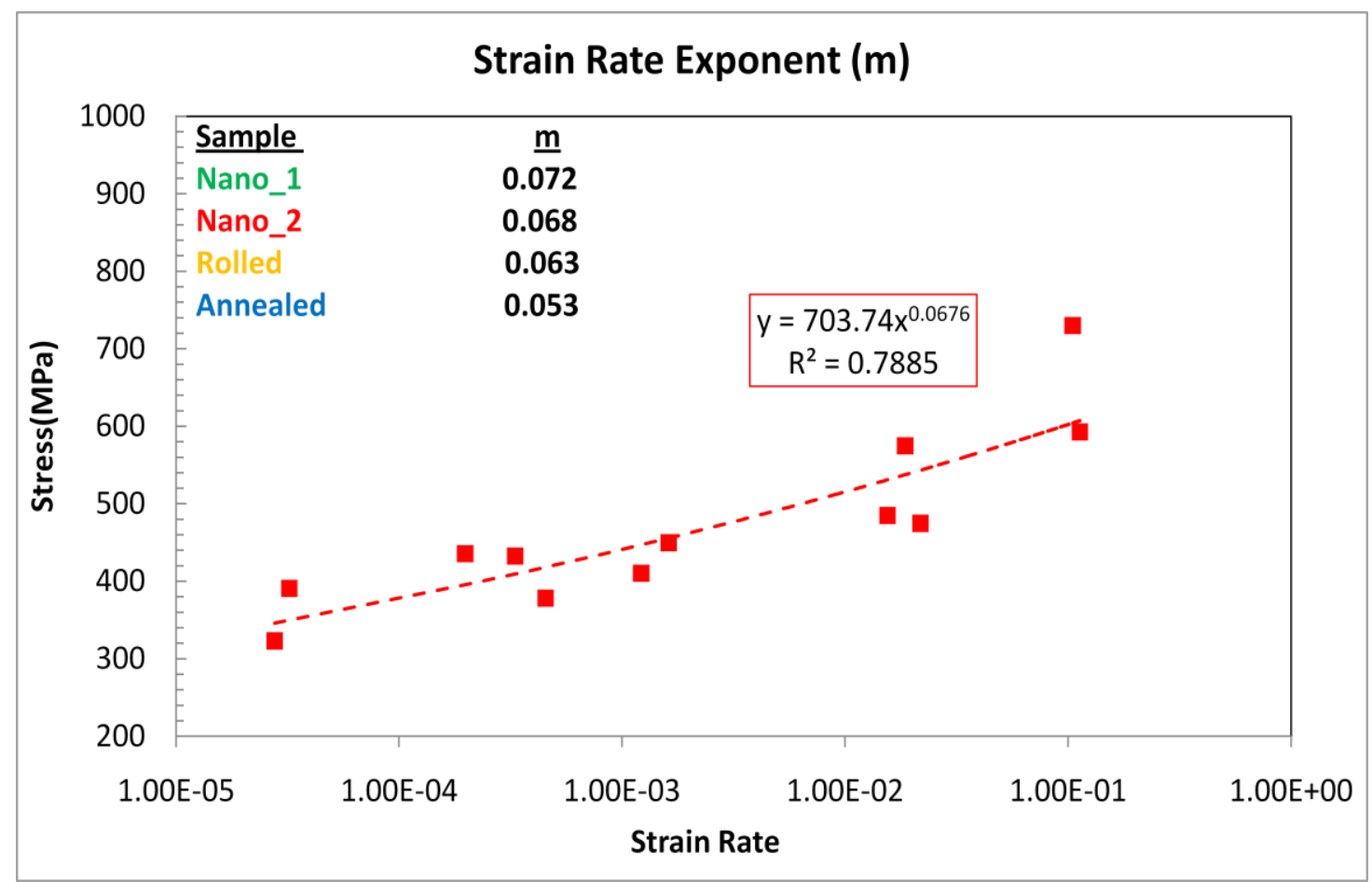

Figure A.3: SRS Exponent of Nano_2 Sample - Tensile Testing

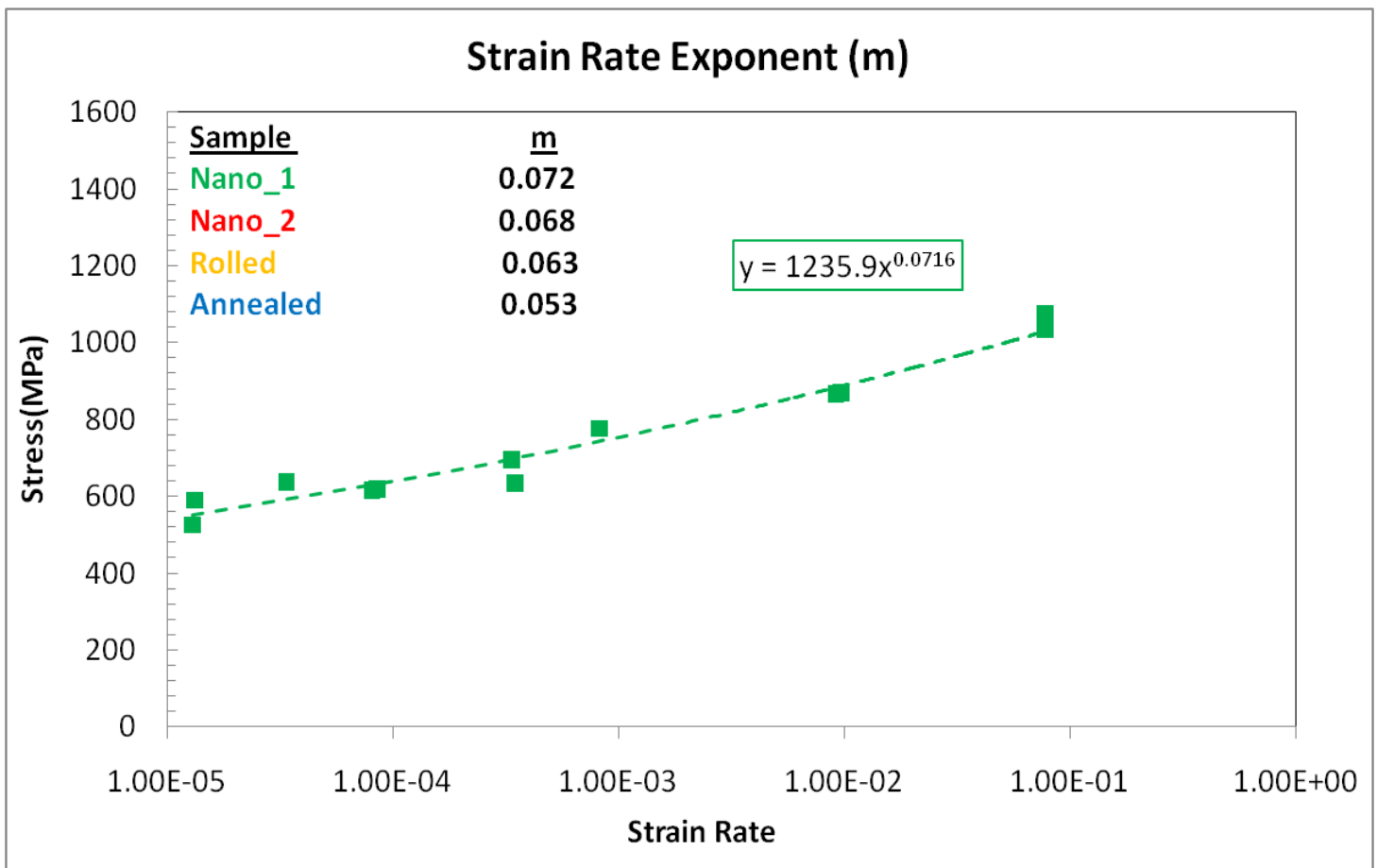

Figure A.4: SRS Exponent of Nano_1 Sample - Tensile Testing 


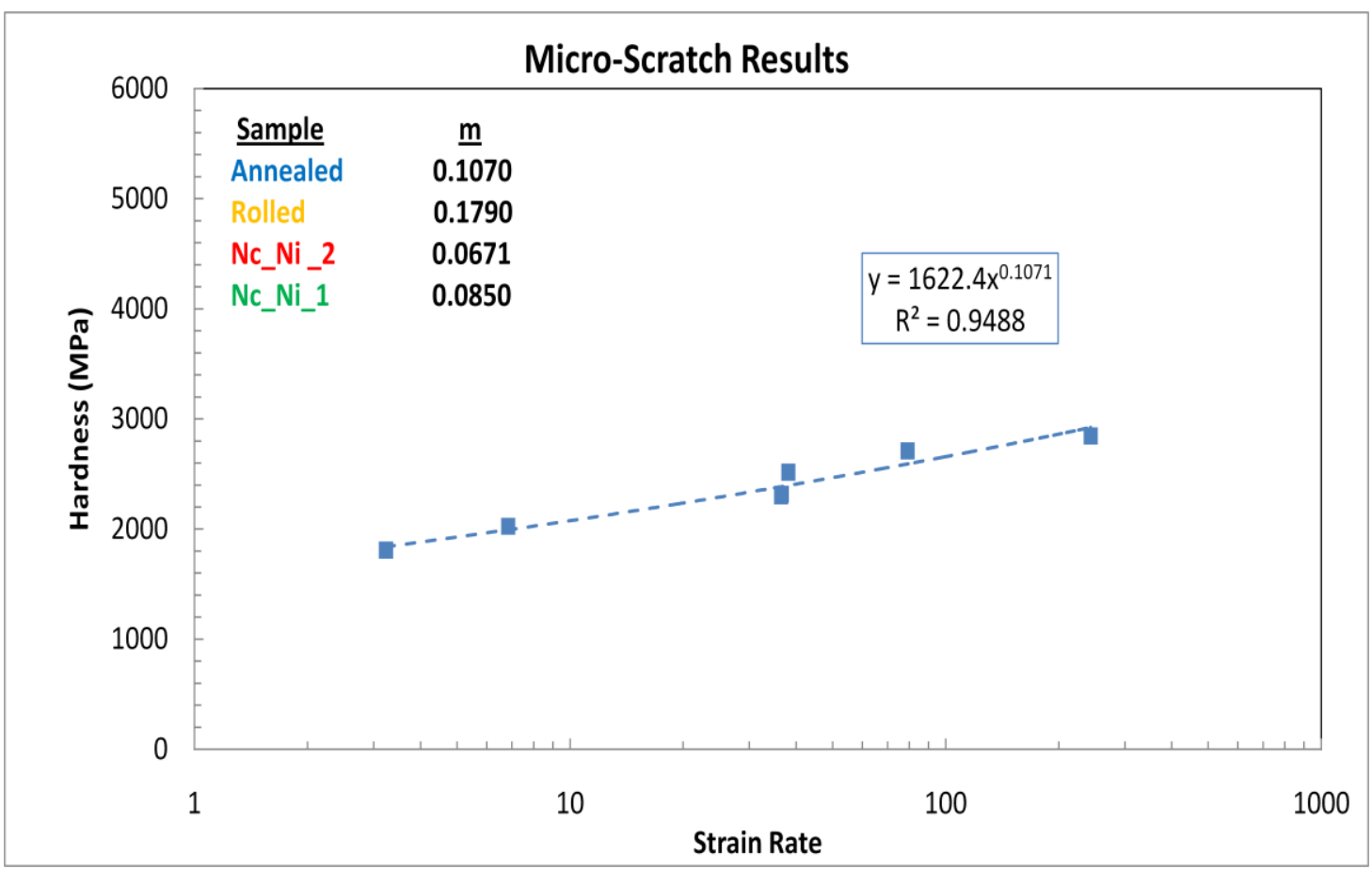

Figure A.5: SRS Exponent of Annealed Sample - Micro-scratch Testing

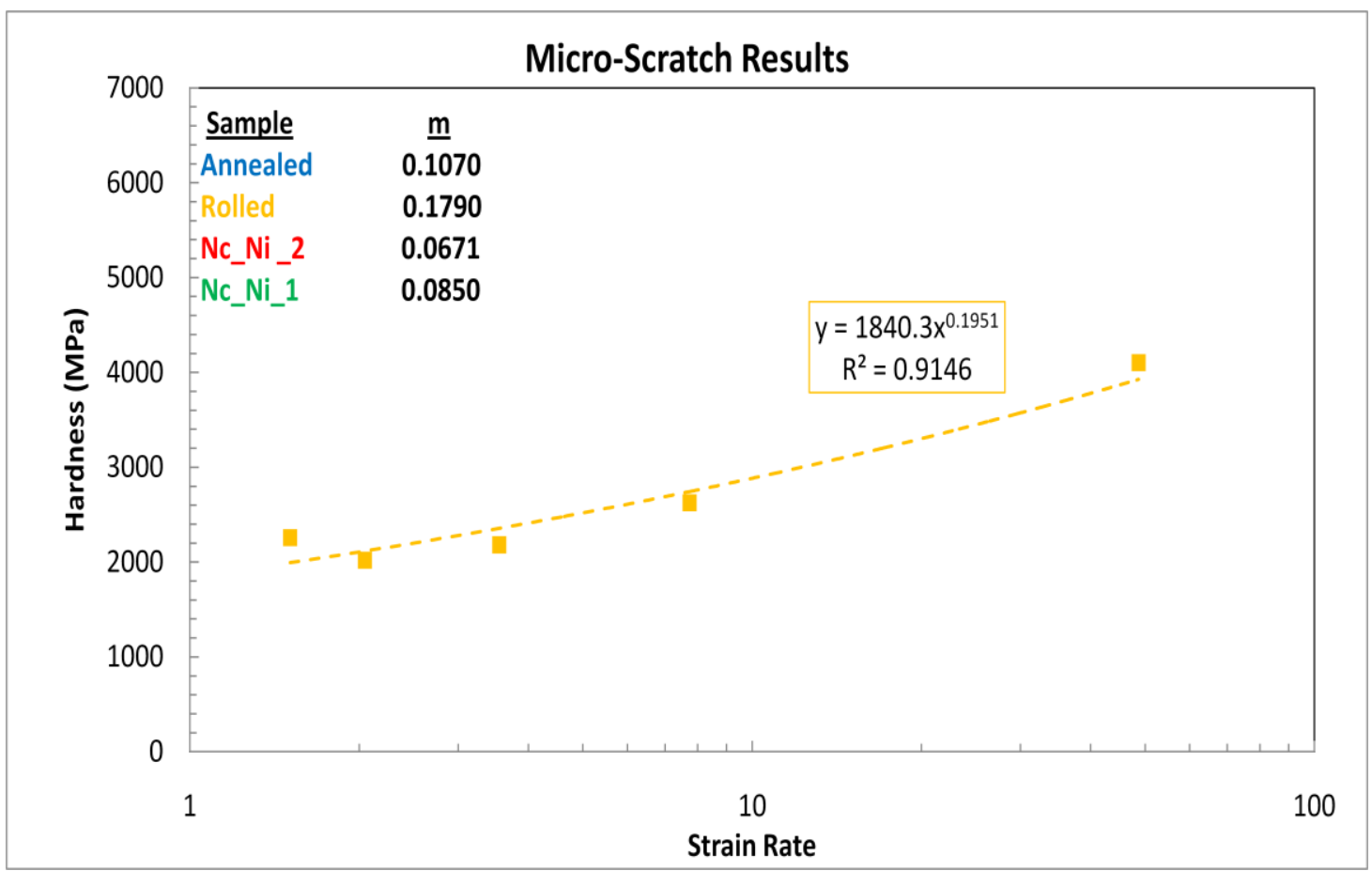

Figure A.6: SRS Exponent of Rolled Sample - Micro-scratch Testing 


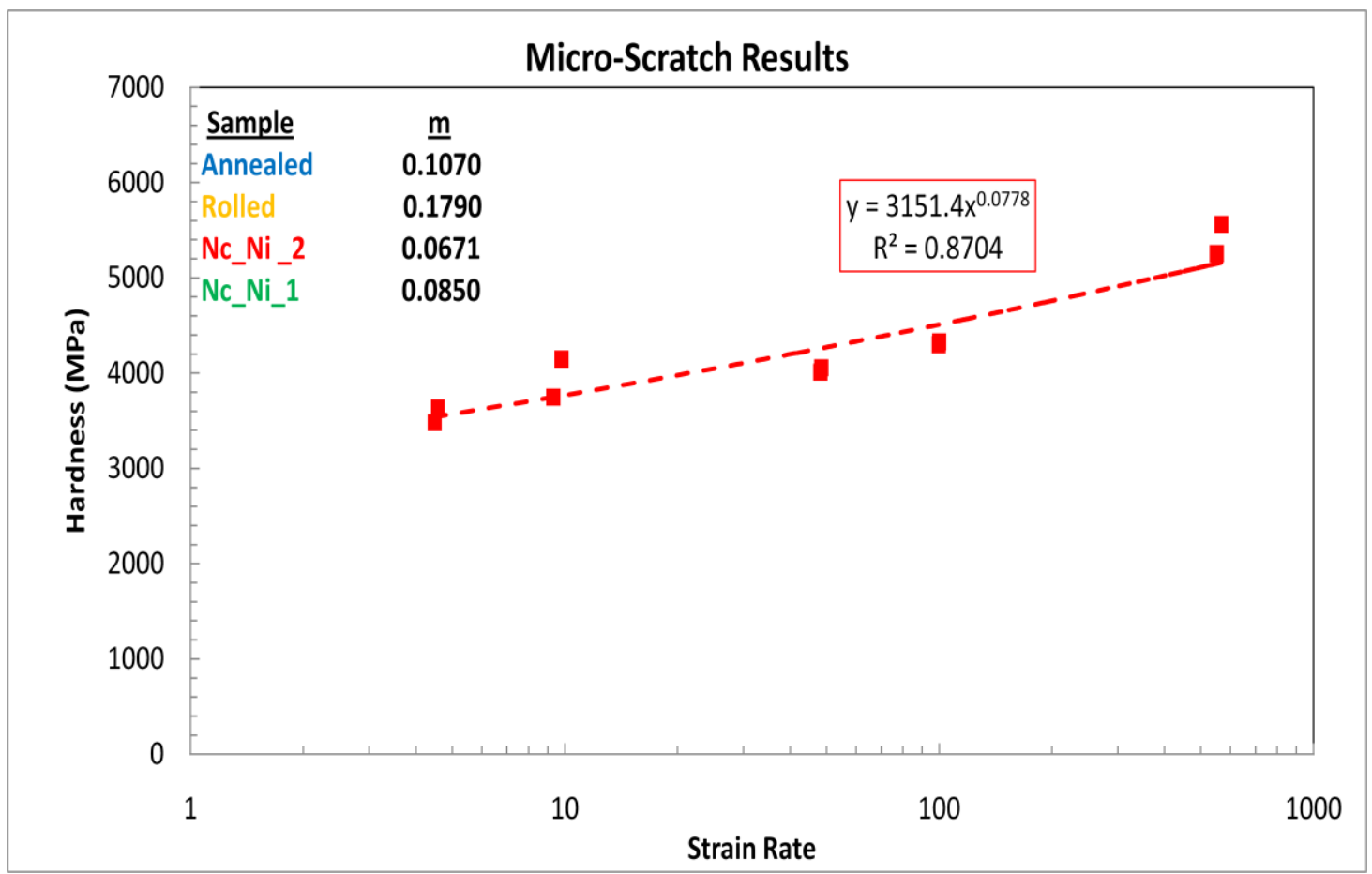

Figure A.7: SRS Exponent of Nano_2 Sample - Micro-scratch Testing

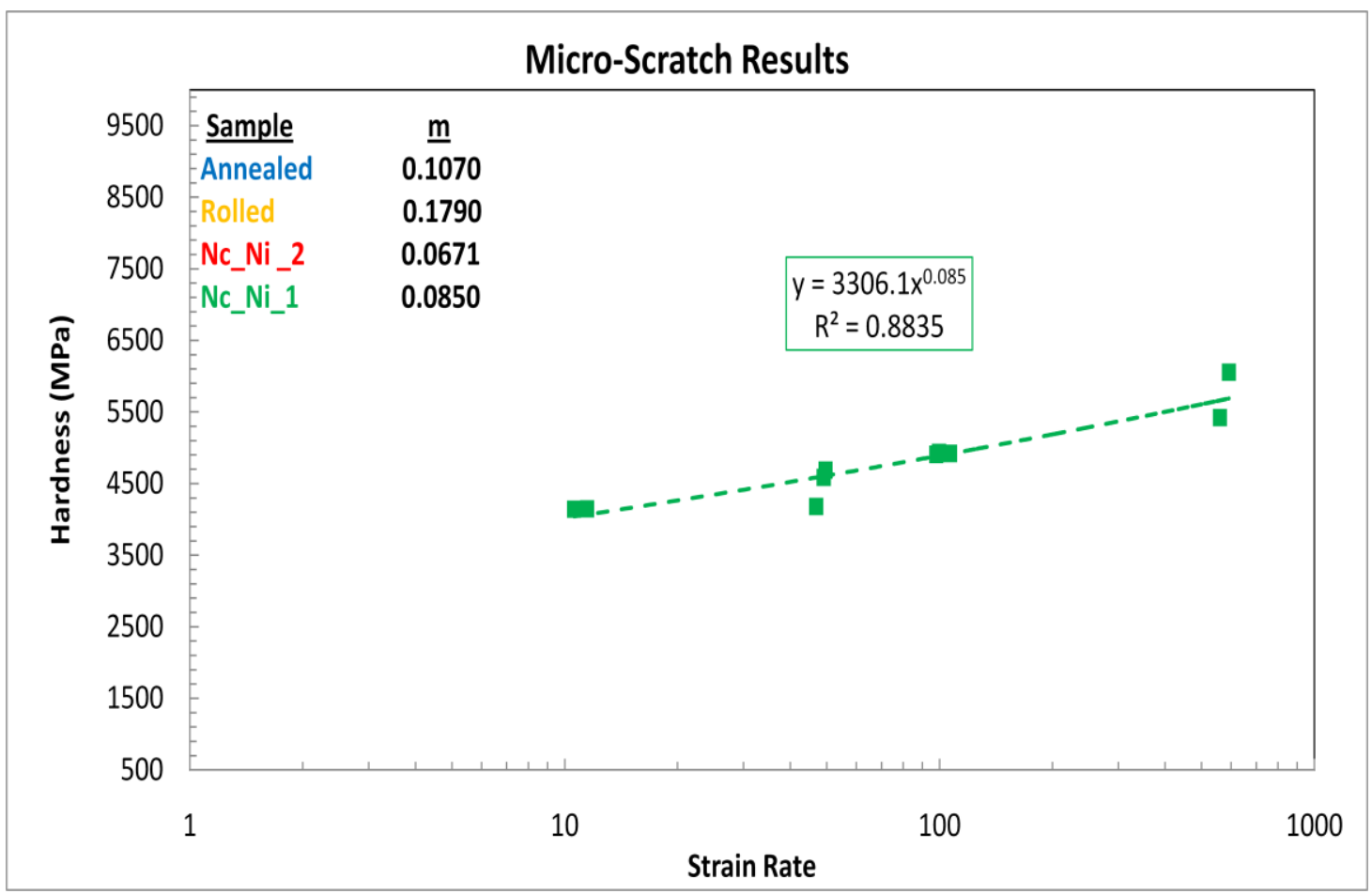

Figure A.8: SRS Exponent of Nano_1 Sample - Micro-scratch Testing 


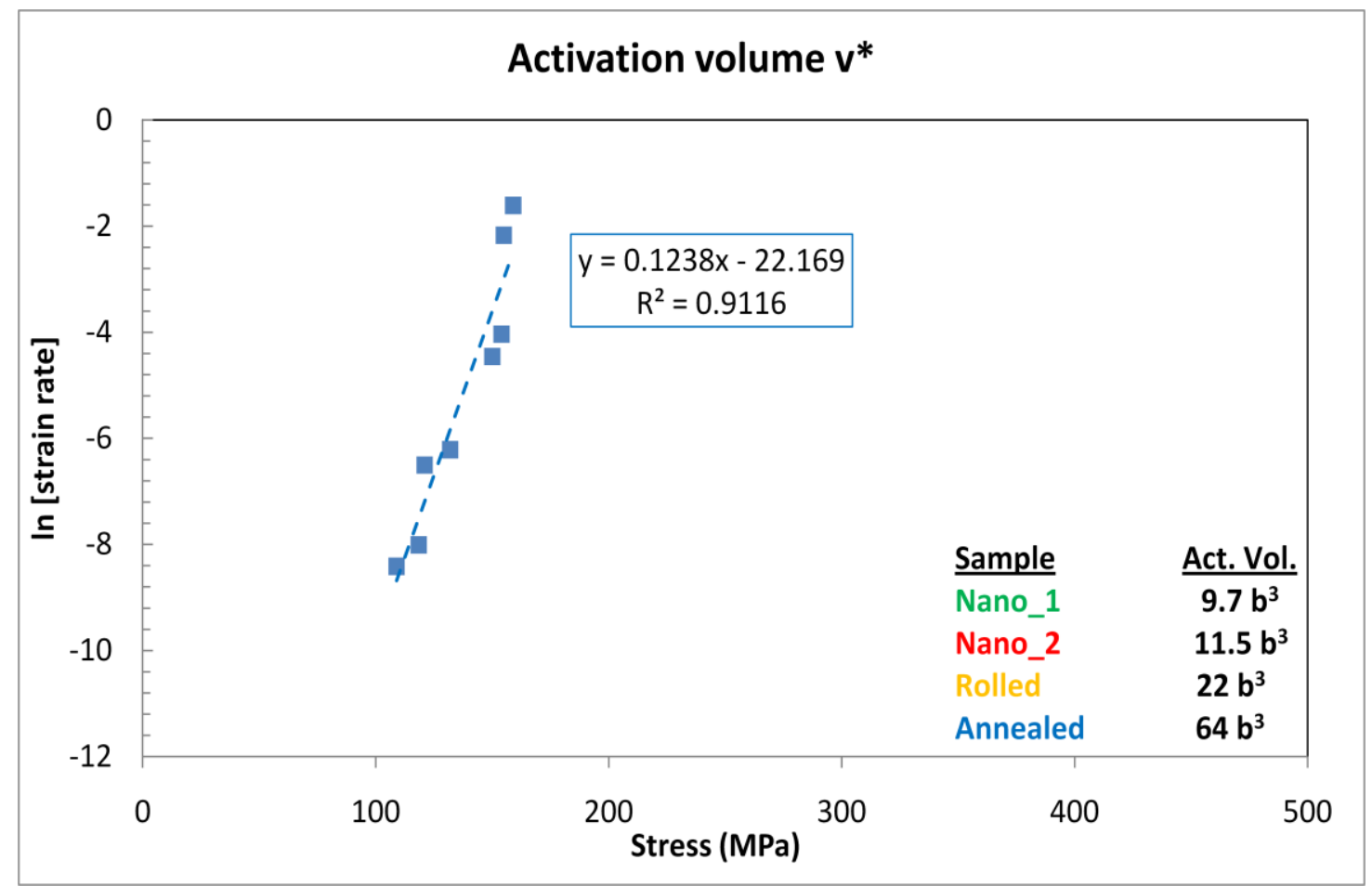

Figure A.9: Activation Volume Annealed Sample

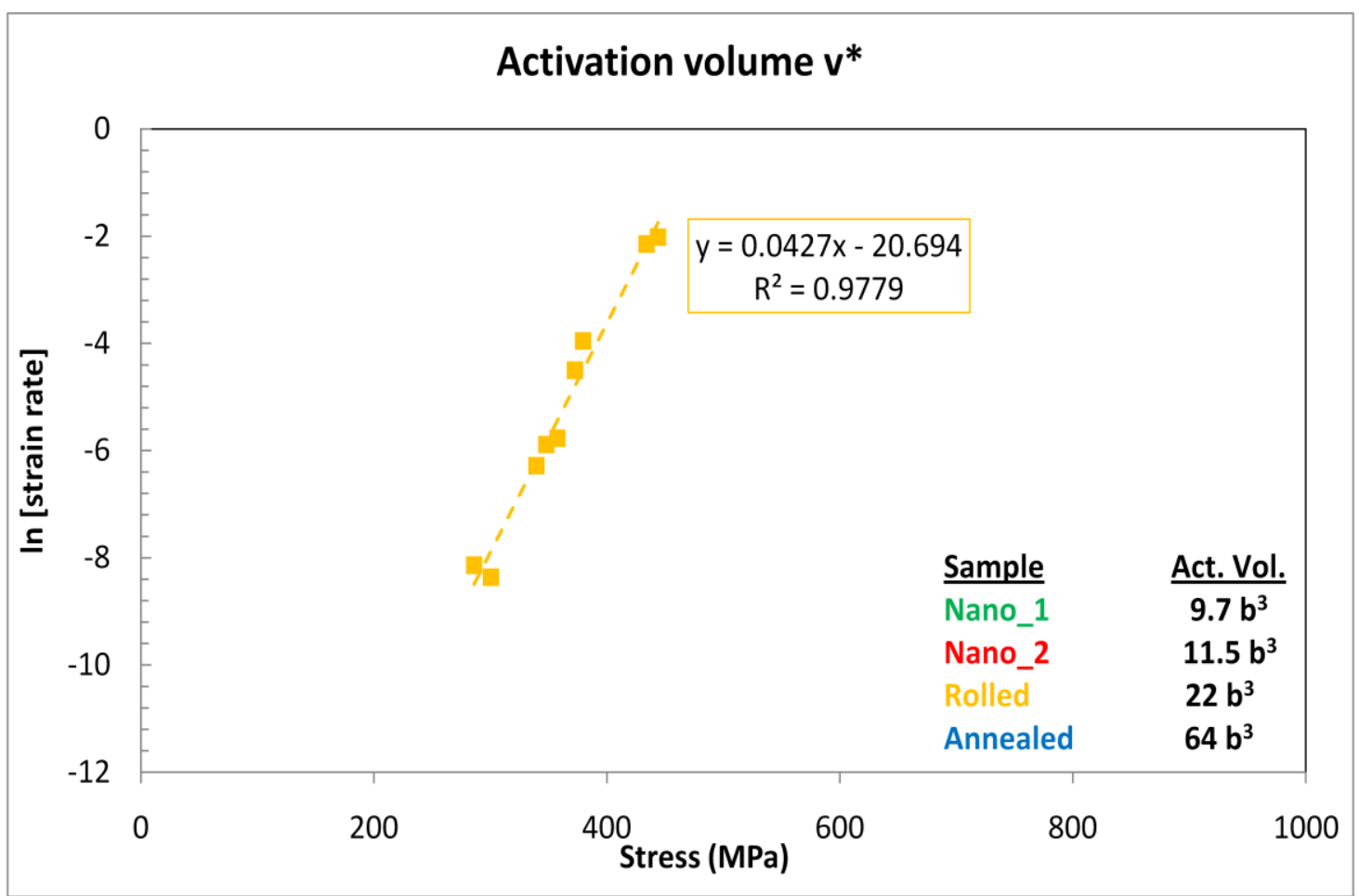

Figure A.10: Activation Volume Rolled Sample 


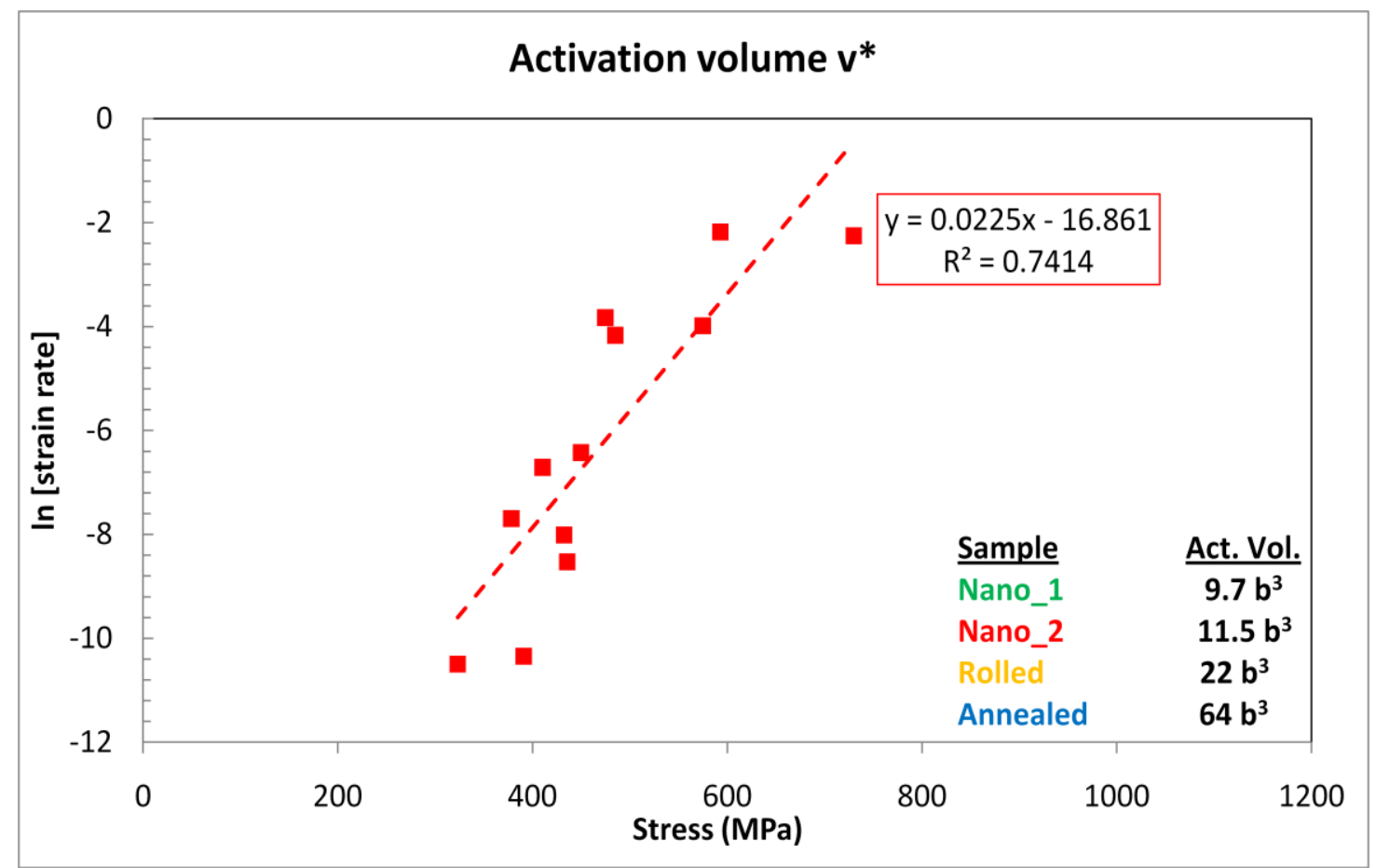

Figure A.11: Activation Volume Nano_2 Sample

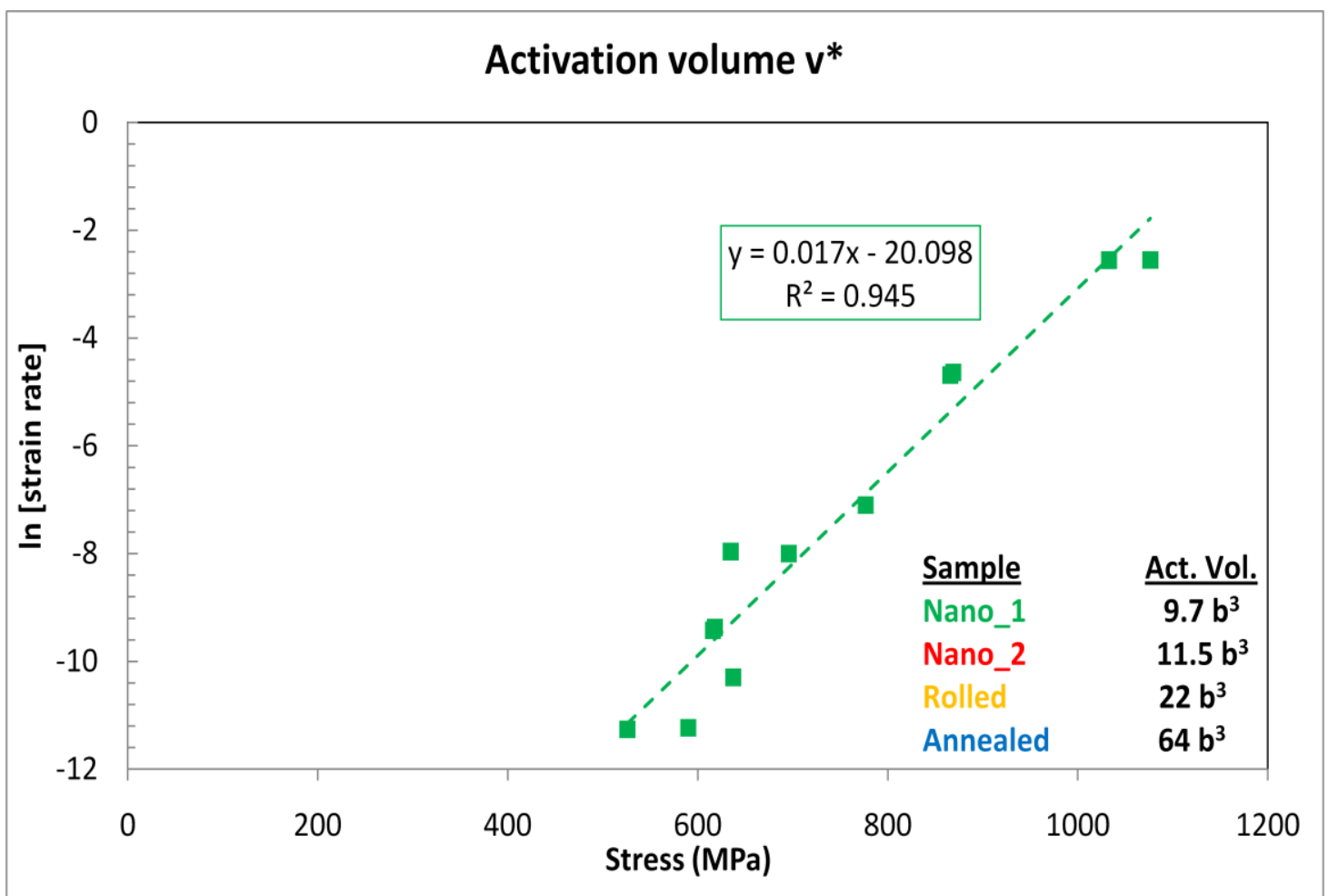

Figure A.12: Activation Volume Nano_1 Sample 